Article

\title{
Advancing Collaborative Water Governance: Unravelling Stakeholders' Relationships and Influences in Contentious River Basins
}

\author{
Rodrigo Rojas ${ }^{1, *(\mathbb{D})}$, Gabriella Bennison ${ }^{2}{ }^{\mathbb{D}}$, Victor Gálvez ${ }^{2}$, Edmundo Claro ${ }^{2}$ \\ and Gabriel Castelblanco ${ }^{3}$ iD \\ 1 CSIRO Land and Water, EcoSciences Precinct, 41 Boggo Road, Dutton Park, Brisbane, QLD 4102, Australia \\ 2 Fundación CSIRO Chile Research, Avenida Apoquindo 4700, Piso 9, Las Condes, Santiago 7500000, Chile; \\ gabriella.bennison@csiro.au (G.B.); v.galvezorellana@uq.net.au (V.G.); edmundo.claro@csiro.au (E.C.) \\ 3 Departamento de Ingeniería Ambiental, Universidad Central, Calle 21 4-40, Bogotá, Colombia; \\ gcastelblancob@ucentral.edu.co \\ * Correspondence: Rodrigo.Rojas@csiro.au; Tel.: +61-07-3833-5600
}

Received: 5 November 2020; Accepted: 21 November 2020; Published: 26 November 2020

\begin{abstract}
Collaborative water governance (CWG) has emerged as a promising framework to tackle water management challenges. Simple identification of participants however is not enough to unravel the intricacies of stakeholders' interlinkages, roles and influences for robust CWG. A clear understanding of the stakeholders' landscape is therefore required to underpin CWG. In this work, we combine stakeholder analysis (SA), social network analysis (SNA) and participatory processes (PP) under a theoretical collaborative governance framework to advance CWG in the contentious Rapel River Basin (RRB), Chile. By combining these techniques, we identified a cohort of leading (and secondary) stakeholders, their relationships and critical roles on basin-wide CWG-enabling networks (collaborative ties, information flows and financial exchanges) and their influence to achieve a shared vision for water planning. The results show members of this cohort perform critical roles (bridging, connecting and gatekeeping) across the networks and in influencing explicit elements of the shared vision. Specific CWG-enabling networks properties indicate a weak adaptive capacity of stakeholders to deal with potential water management challenges and strong prospects for sharing innovative ideas/solutions and achieving long-term water planning goals. A major CWG implementation challenge in the RRB is the lack of a leading organisation. One way forward would be formally organising stakeholders of the identified cohort to advance CWG in the RRB. By implementing the methodological framework, we facilitated social learning, fostered trust among stakeholders and mobilised efforts towards implementing CWG in practice in the contentious RRB.
\end{abstract}

Keywords: water governance; collaboration; social network analysis; participatory process; shared vision; stakeholder analysis; network properties; social learning

\section{Introduction}

Water is a key resource for sustaining livelihoods, producing food, generating energy and enabling healthy ecosystems and the services which they provide [1]. Increasing demands, population growth, climate variability, competing uses and interdependencies across multiple sectors (e.g., water-energy-food nexus) are challenging the way in which water resources have traditionally been managed [2,3]. 
'Water crises' and 'water supply crises' have consistently been ranked among the five highest global risks since 2012 [4] with the international community generally adhering to the Global Water Partnership's statement that 'the water crisis is often a crisis of governance' $[5,6]$. Water governance has been interpreted in a number of different ways $[7,8]$ but can be broadly defined as 'the set of rules, practices, and processes (formal and informal) through which decisions for the management of water resources and services are taken and implemented, stakeholders articulate their interest and decision-makers are held accountable' [9]. Pahl-Wostl [10] suggested that failure in water governance at multiple levels has triggered many of the water-related problems, as much as the resource itself, thus threatening water security [11]. In a similar argument, Zwarteveen et al. [12] suggested that water governance is mostly informed by ideological hypotheses about how water resources should be managed, rather than by a thorough understanding of how it should work in practice.

In recent years, the concept of Collaborative Water Governance (CWG), which builds upon formal approaches to collaborative governance (e.g., $[13,14])$, has been championed as a promising response to water management challenges $[15,16]$. We understand CWG as a combination of collaboration (i.e., cooperation among stakeholders to achieve common goals) and water governance, and thus as an attempt to 'operationalise' water governance in practice. Under this concept, stakeholders are encouraged to share responsibility and contribute more widely to the management of water resources at all levels, embracing bottom-up processes of collaboration and knowledge sharing (e.g., [17]). These processes should take into consideration local knowledge, inclusion and transparency principles [5,18-20], and should therefore be underpinned by participatory processes facilitating collaboration in order to build consensus around a shared vision (outcome) for future water planning (e.g., [21]).

As CWG departs from traditional hierarchical, command-and-control frameworks typically used in natural resource management [22-24], it is not surprising this approach has been reported to improve the institutional capacity to manage conflicts [16]. Despite other reported benefits of CWG (e.g., increased inclusion and participation and effective knowledge transfer), some authors acknowledge a clear gap between theory and practice for water management and planning [25]. At the same time, important implementation challenges of CWG have been reported in the literature: e.g., power imbalances and lack of coordination among stakeholders; funding, time and institutional constraints; conflict resolution needs; and questioning about transparency, accountability and authority [16,26-28].

An important step towards closing the gap between theory and practice for 'good' CWG is therefore understanding the formal and informal rules that underlie system interactions, establishing boundaries and identifying linkages and relationships between stakeholders [29]. The latter suggests that a good understanding of the 'stakeholder ecosystem', including stakeholders' interests, knowledge and relationships, among others, is a necessary condition for successful implementation of CWG (e.g., [28,30-35]). These stakeholders' interactions will often lead to the formation of (formal or informal) social (collaborative) networks in the context of CWG [24]. Research suggests these networks play important roles in facilitating knowledge and information transfer, resources mobility and use, and conflict resolution [36]. As highlighted by Ogada et al. [24], however, the analysis of these networks and stakeholders' interactions in terms of influences, interests and participation at basin scales has been limited. This therefore has the potential to jeopardise arrangements to successfully implement and advance CWG in practice.

In this work, we hypothesise that there exist stakeholders holding key roles in basin-wide CWG-enabling networks and in the achievement of a shared vision for future water planning, and therefore they should be included in potential arrangements to implement CWG. For this, we combine the theoretical collaborative governance framework of Ansell and Gash [13] as basis for CWG, with stakeholder analysis (SA), social network analysis (SNA) and a participatory process (PP) to disentangle stakeholders' interactions and influences in the Rapel River Basin (RRB) in central Chile. We embrace the theoretical framework of Ansell and Gash [13] for CWG since: (a) it closely fits the collaborative landscape in the 
RRB (and Chile in general, see, e.g., [37]); and (b) its driving conditions show a clear relationship with basin-wide networks promoting CWG (information flows, collaboration ties and financial exchanges, see Section 3 and $[24,30,36]$ ), thus providing a means to test our hypothesis. The objective of this work is to set the foundational step to advance CWG through disentangling stakeholders' influences and relationships in the contentious RRB and to advance our understanding about CWG implementation challenges identified in the literature (see, e.g., [16,26]).

To achieve this, we implemented a PP underpinned by circles of influences [38,39] and SA [40] to identify key stakeholders and elements of a shared vision for future water planning in the RRB. We then applied SNA [41]: (a) to quantitatively describe stakeholders' relationships related to basin-wide CWG-enabling networks such as financial exchanges, collaboration ties and information flows; and (b) to identify stakeholders' influences in enabling the achievement of specific elements of the shared vision. SNA has recently been used in the analysis of water governance/management aspects such as urban [34] and natural [24] water systems, informal social networks as a new form of water governance [42] and understanding water infrastructure planning [43], participatory scenario planning [44] and collaborative governance for floodplain management [35], among others.

Previous research shows important deficiencies in terms of water governance in Chile [45-48], which is likely to be a key factor behind the country's poor performance in terms of Integrated Water Resources Management (IWRM) implementation [49]. Currently, participatory processes for water management are still absent in decision-making at local and national scales. Recently, Gálvez et al. [37] identified the lack of basin-scale shared visions as a barrier for collaborative water governance in a basin in northern Chile. Similarly, Dourojeanni et al. [50] argued that the absence of 'shared visions' at basin-scale is due to the lack of basin authorities/organisations. Despite the particularities of the Chilean context, the situation analysed in the contentious RRB (e.g., increasing pressure on water resources, lack of stakeholder organisation, lack of a shared vision for water planning and competing water uses, among others) is likely to reflect similar conditions in other poorly managed basins around the globe, thus providing some generality to our findings.

The novelty of this work lies therefore in contributing to closing the gap between theory and practice of CWG implementation by advancing our understanding about solving implementation challenges and implementing a first-ever bottom-up visioning process for the RRB based on the robust identification of multiple stakeholders with a relevant role to achieve this vision.

The following sections describe the methods employed, including a description of the case study, results from the circles of influence and social network analyses. Finally, we analyse results in the context of international literature and provide concluding remarks.

\section{Case study: Rapel River Basin}

The Rapel River Basin (RRB) is located in Chile's central zone (Figure 1). It consists of four sub-basins covering a total area of $13,766 \mathrm{~km}^{2}$ with average annual precipitation ranging between 450 and $1050 \mathrm{~mm} /$ year, and a mixed pluvial-nival hydrological regime. Average annual river discharges (1981-2010) in the major tributaries Cachapoal and Tinguiririca rivers are 89.0 and $50.2 \mathrm{~m}^{3} / \mathrm{s}$, respectively [51] (see Figure 1). The basin has a regulation capacity of $932 \mathrm{Mm}^{3}$ provided by the Rapel (hydropower, $695 \mathrm{Mm}^{3}$ ) and the Convento Viejo reservoirs (irrigation, $237 \mathrm{Mm}^{3}$ ). 


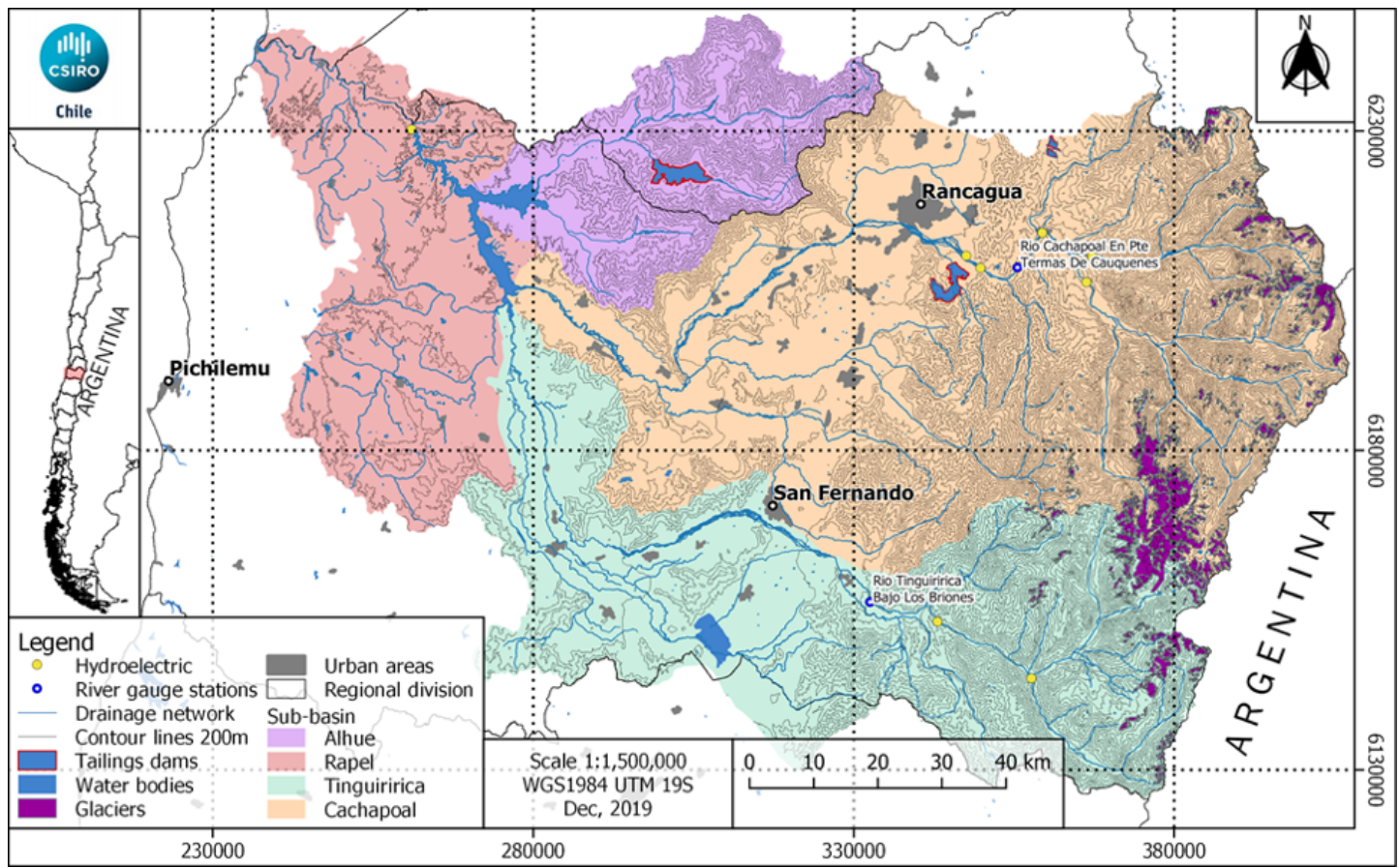

Figure 1. Location of the RRB and its main sub-basins and spatial attributes.

Water consumption in the RRB is approximately $45 \mathrm{~m}^{3} / \mathrm{s}$ and sustains diverse uses including urban/rural water supply and sanitation, mining activities, hydropower and agriculture/agroindustry, with the latter accounting for $93 \%$ of water consumption [52]. The Chilean Water Authority has recently reported substantial decreases in average precipitation and river flows ( $45 \%$ and $51 \%$, respectively) in comparison to historic conditions (1981-2010) [53], thus adding to the pressure on water resources in the basin. This situation is expected to worsen given climate change predictions suggesting increases in temperature between 1.5 and $2.5{ }^{\circ} \mathrm{C}$ and decreases in average annual rainfall between $10 \%$ and $20 \%$ over the near future (2041-2060) for a high emission scenario (RCP 8.5) [54].

Water management in the RRB is governed by the 1981 Chilean Water Code. This code is based on free-market rules [55] and has provided legal security for private investments in the water sector; however, it has been less effective in operating water markets and in addressing aspects such as conflict resolution, environmental protection and internalisation of economic, environmental and social externalities [56]. Recently, other limitations of this legal framework related to hindering collective management, increasing power asymmetries and threatening communitarian water management have been highlighted $[57,58]$. In practice, active water management and use regulation have been transferred to private stakeholders (owners of water rights) through bargaining for resource allocation, with government agencies and social organisations having a limited role in effective management and regulation $[59,60]$. This has been translated in the private sector having a relevant role in decision making for water resources management in the RRB (and Chile in general), for example, by driving allocation of water resources, leading the conformation of water user organisations and promoting investment in the sanitary sector, among others. For a comprehensive review of operational and institutional aspects of water management and policy in Chile, the reader is referred to [59-62]. 


\section{Methods}

Under the umbrella of the theoretical framework for collaborative governance of Ansell and Gash [13], a three-tiered approach including stakeholder analysis, participatory process and social network analysis was implemented. Figure 2 shows the methodological framework employed in this work.

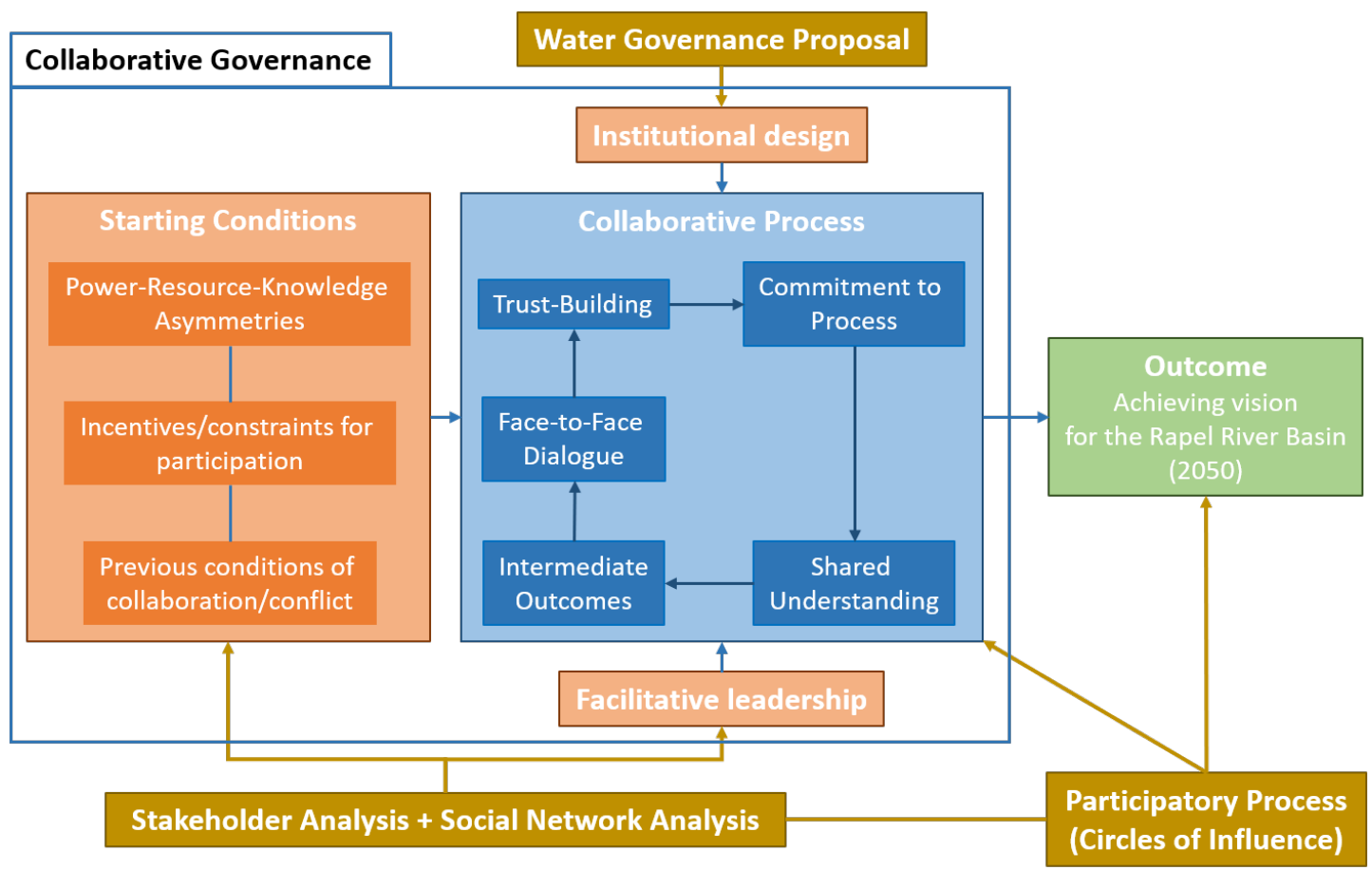

Figure 2. Methodological framework used in this article: three-tiered approach (SA, SNA and PP) and theoretical collaborative governance framework of Ansell and Gash (2008) (adapted from [37]).

Ansell and Gash [13] proposed a collaborative governance framework, which separates the collaborative process itself from external drivers that influence the success (or failure) of collaborative governance (i.e., facilitative leadership, starting conditions and institutional design). Using SA, we identified potential stakeholders for facilitative leadership (i.e., steering CWG) and to set up the participatory process. By using SNA, we disentangled the stakeholders' relationships regarding basin-wide CWG-enabling networks (see, e.g., [24]) and their influences on achieving the elements of the shared vision. The PP helped us facilitate the collaborative process itself by promoting face-to-face dialogue, building trust and developing commitment and shared understanding. In addition, PP allowed the identification of key elements reflecting stakeholders' interests, which were grouped around a shared vision for the basin (an outcome of CWG). The third external driver of the collaborative governance framework (institutional design) was not addressed in this work as it is the subject of separate research on institutional/legal frameworks proposed for the RRB.

In the following sections, details of the implementation of the three-tiered approach are provided.

\subsection{Stakeholder Analysis and Participatory Process}

Stakeholders in the RRB were identified using analytical categorisation (top-down approach) [40] for stakeholder analysis (SA) aiming at obtaining three CWG-related groups: (i) productive sectors such as agriculture, agroindustry, mining and energy; (ii) state agencies with competencies in water management/regulation; and (iii) academia, social and non-governmental organisations. This initial list 
was further complemented by snowball sampling to include additional stakeholders deemed relevant during initial participatory meetings/interviews.

To guide the participatory process (PP), we employed the circles of influence approach $[1,38,63,64]$. This approach facilitates the participatory process by placing a limit on numbers but not on the influence of specific groups around concentric organisational structures [65]. The definition of the circles of influence emerged from conducting the SA and initial workshop sessions. Figure 3 shows the structure of the PP implemented in the RRB: (i) The inner circle (A) consisted of the research team and key representatives of the Regional Water Users Board and the Regional Water Authority. The role of this group was to implement the technical aspects of the PP as well as to develop research activities and report outcomes of this process. (ii) The second inner circle (B) comprising 16 stakeholders representative of key water sectors in the RRB was identified iteratively during initial working sessions using a snowball sampling approach. This group was composed of six members of the public sector, seven members of the private sector and three members of academia/civil society. The primary role of this group was to support the decision-making process, steer participatory discussions and sessions towards broad interests/challenges, validate results for discussion with the outer circle (C) and provide insight/feedback on critical issues of the research through regular meetings and workshops. (iii) The outer circle (C) consisted of ca. 120 stakeholders. The role of this group was to provide relevant information and local knowledge through attendance to extended participatory workshops. Seven extended participatory workshops (comprising all circles of influence) and 14 working sessions (comprising circles of influence A and B) were implemented over a period of 36 months.

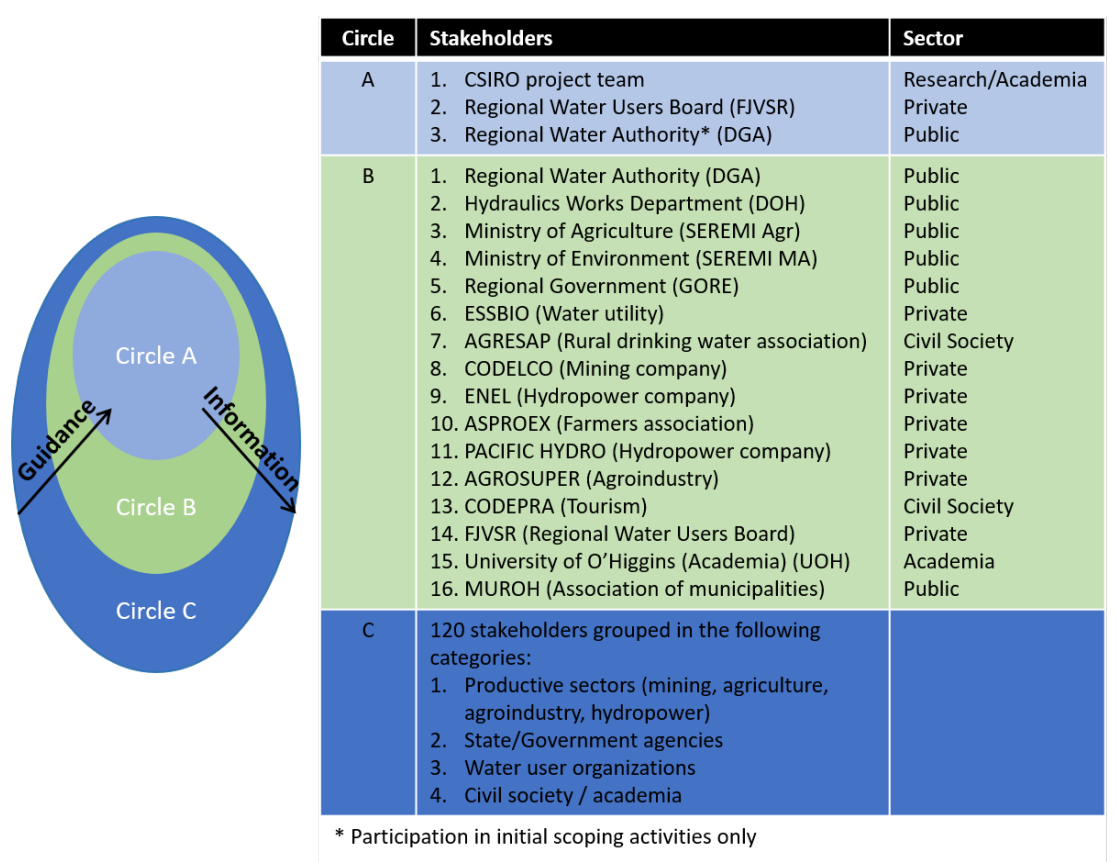

Figure 3. Circles of influence defined to guide the participatory process in the RRB. Circle B was used as proxy for SA and SNA.

By using circle B as a proxy, an interest-influence map was initially developed together with representatives of the Regional Water Authority/Water Users Board by discussing the relevance of stakeholders regarding water-related aspects and CWG. This initial mapping was further iterated with members of circle $B$ and finally validated with circle $C$ during participatory workshops. It is important to note that the absolute position of stakeholders in the interest-influence grid is secondary. 
Instead, stakeholders' relative position in relation to one another as well as their location in one of the four quadrants, are the basis for the analysis.

\subsection{Shared Vision}

We used the PP to define a shared vision for the RRB over a medium- to long-term horizon (2050) as an overarching outcome of CWG. To achieve this, we followed a similar approach as described by Schneider and Rist [66]: (1) identify stakeholders' objectives, concerns and challenges; (2) organise a series of participatory workshops, working sessions, questionnaires and surveys; (3) refine and distil alternative visions and key elements; and (4) develop a shared vision narrative.

A Treemap [67] was developed to summarise the most recurrent elements raised by stakeholders during interviews/surveys and to help articulate the vision around specific topics. The shared vision was organised around five water-related dimensions, including 21 specific elements. These elements were used to analyse stakeholders' influence on achieving the shared vision.

\subsection{Social Network Analysis}

We applied Social Network Analysis (SNA) [41,68] to obtain fine-grained insights into stakeholder relationships and influences on key basin-wide networks (collaboration ties, information flows and financial exchanges) relevant to CWG implementation (see, e.g., [24]). These networks were linked back to the starting conditions (knowledge asymmetries, incentives for participation and history of collaboration) and facilitative leadership shown in the methodological framework (Figure 2). SNA provided network- and stakeholder-level quantitative metrics describing stakeholders' relationships and roles in the networks.

SNA was applied using circle B as a proxy (see Figure 3). We implemented two relationship mapping/ survey exercises to each member of circle B to determine stakeholders' interactions (direction and frequency) with the other 15 members of circle B for each of the networks. Participants were given the opportunity to identify other stakeholders with whom they interacted but that were not listed in circle B. For a clear linkage with the starting conditions of the theoretical framework (Figure 2), stakeholders were asked about information flows (e.g., knowledge asymmetries, accessing and sharing public/private data, accessing specialised reports, etc.), collaborative ties (e.g., history of informal and formal collaboration, agreements, invitation/participation in meetings/projects, etc.) and exchange of financial resources (e.g., incentives for participation, donations, payment of permits, grants, etc.). Direction determined the orientation of the interaction, which was multidirectional or unidirectional, or as a donor or recipient in the case of financial resources. Frequency reflected stakeholders' interactions on two levels: high-frequency (less than six months) or low-frequency (more than six months). When reciprocal stakeholders reported differences between the individual perception of frequencies, the lowest frequency was employed. Stakeholders in circle B were then asked to rank their institution's level of influence towards achieving each of the 21 elements identified in the shared vision under three levels: no influence, low-influence and high-influence.

Data from these questionnaires were coded as square matrices, termed adjacency matrices, with columns and rows defined as the stakeholders identified (1-mode). The matrix reflecting the influence of stakeholders over the elements of the vision was a 2-mode matrix, where rows were stakeholders and columns the 21 elements of the vision. We employed UCINET software [69] to perform SNA and calculate a series of metrics (see Table 1) reflecting connectivity, proximity, control over material flows of attributes (e.g., funds and information) and relevance in terms of connections to key stakeholders. 
Table 1. SNA centrality metrics and definitions used in the analysis of basin-wide networks in the RRB.

\begin{tabular}{ll}
\hline SNA Metric & Definition \\
\hline Degree Centrality & $\begin{array}{l}\text { Number of connections (input and output) that a stakeholder has in the network. Represents the } \\
\text { number of connections and therefore connectivity within the corresponding network. }\end{array}$ \\
\hline Closeness Centrality & $\begin{array}{l}\text { Shortest distance between each stakeholder. Greater closeness centrality implies higher proximity and, } \\
\text { consequently, a greater capacity to access other stakeholders through the network. }\end{array}$ \\
\hline Betweenness Centrality & $\begin{array}{l}\text { Percentage of the shortest routes between stakeholders passing through a particular stakeholder. } \\
\text { Greater betweenness centrality implies greater importance in the control of material flow; that is, } \\
\text { the stakeholder is key in the distribution of the material flow (collaboration, information and/or } \\
\text { financial resources). }\end{array}$ \\
\hline Eigenvector Centrality & $\begin{array}{l}\text { Weighting of the number of connections due to the relevance of the stakeholders they connect. The } \\
\text { stakeholders connected to more influential stakeholders (i.e., better connected) have a greater centrality } \\
\text { of their own value. Peripheral stakeholders, therefore, have a lower centrality of their own value. }\end{array}$ \\
\hline
\end{tabular}

\section{Results}

\subsection{Stakeholder Analysis and Interest-Influence Map}

SA identified 136 stakeholders from public, private and academia/civil society organisations in the RRB. These stakeholders were categorised into two main circles, B (16) and C (120), based on the circles of influence approach (see Figure 3). Figure 4 shows the bi-dimensional mapping of interest-influence using the inner circle B as a proxy.

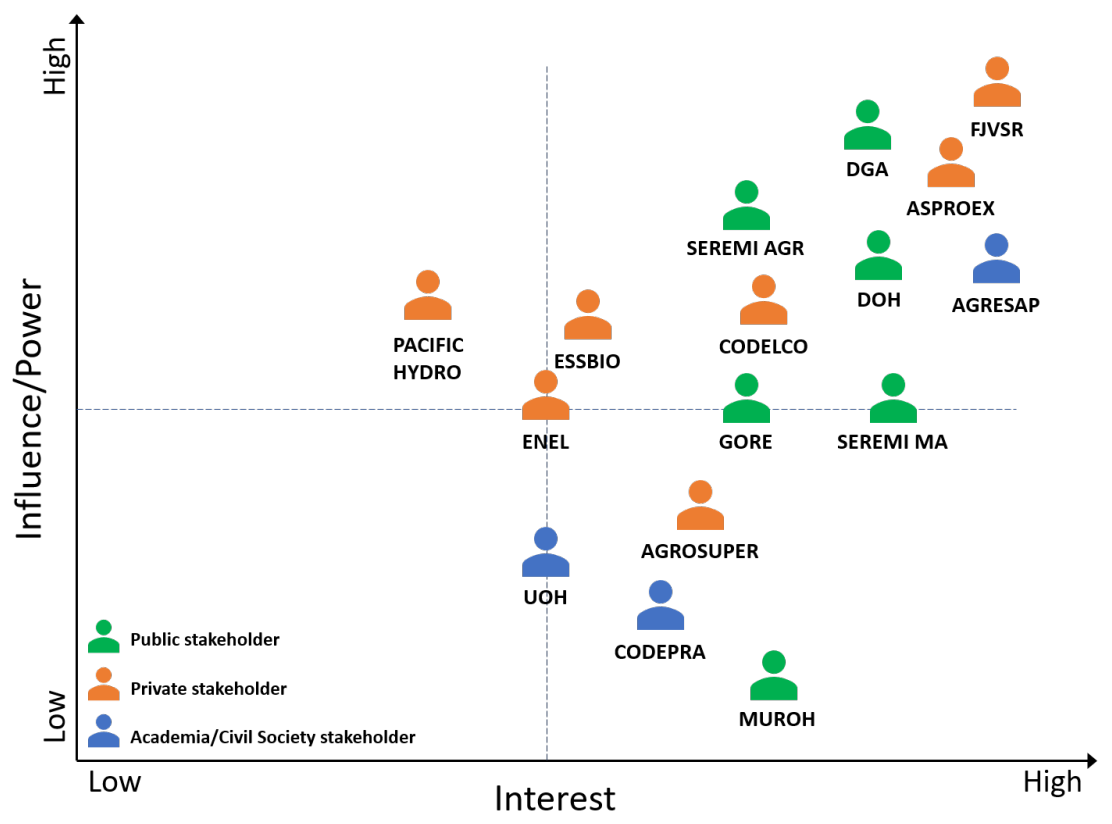

Figure 4. Influence-Interest map for stakeholders of the circle of influence (B) in the RRB.

Figure 4 shows a configuration where half of the members of circle B are in the quadrant high-influence-high-interest. In this quadrant, the private sector is predominant, followed by the public sector and only one civil society stakeholder. The Regional Water Users Board (FJVSR), Regional Water Authority (DGA) and the Farmers Association (ASPROEX) are identified as the most influential and interested stakeholders with regards to CWG in the RRB. In the quadrant low-influence-high-interest, we observe mostly public and academia/civil society stakeholders with a high stake in water resources but 
without water rights for use. Finally, it is interesting to note the relative location of stakeholders related to the hydropower sector (ENEL and PACIFIC HYDRO), who tend towards high-influence and low-interest in comparison to other stakeholders.

\subsection{Shared Vision}

Figure 5 summarises in a Treemap the most recurrent points raised by stakeholders during participatory workshops/working sessions. The topics raised were grouped into five water-related dimensions: water and institutions, water availability, water use, water and society and water and environment (in order of relevance). Several transversal topics crossed over more than one category. The analysis indicates that the most recurrent topic relates to water and institutions, particularly, the need for a basin-scale governing body and the involvement of all water users in the decision-making process.

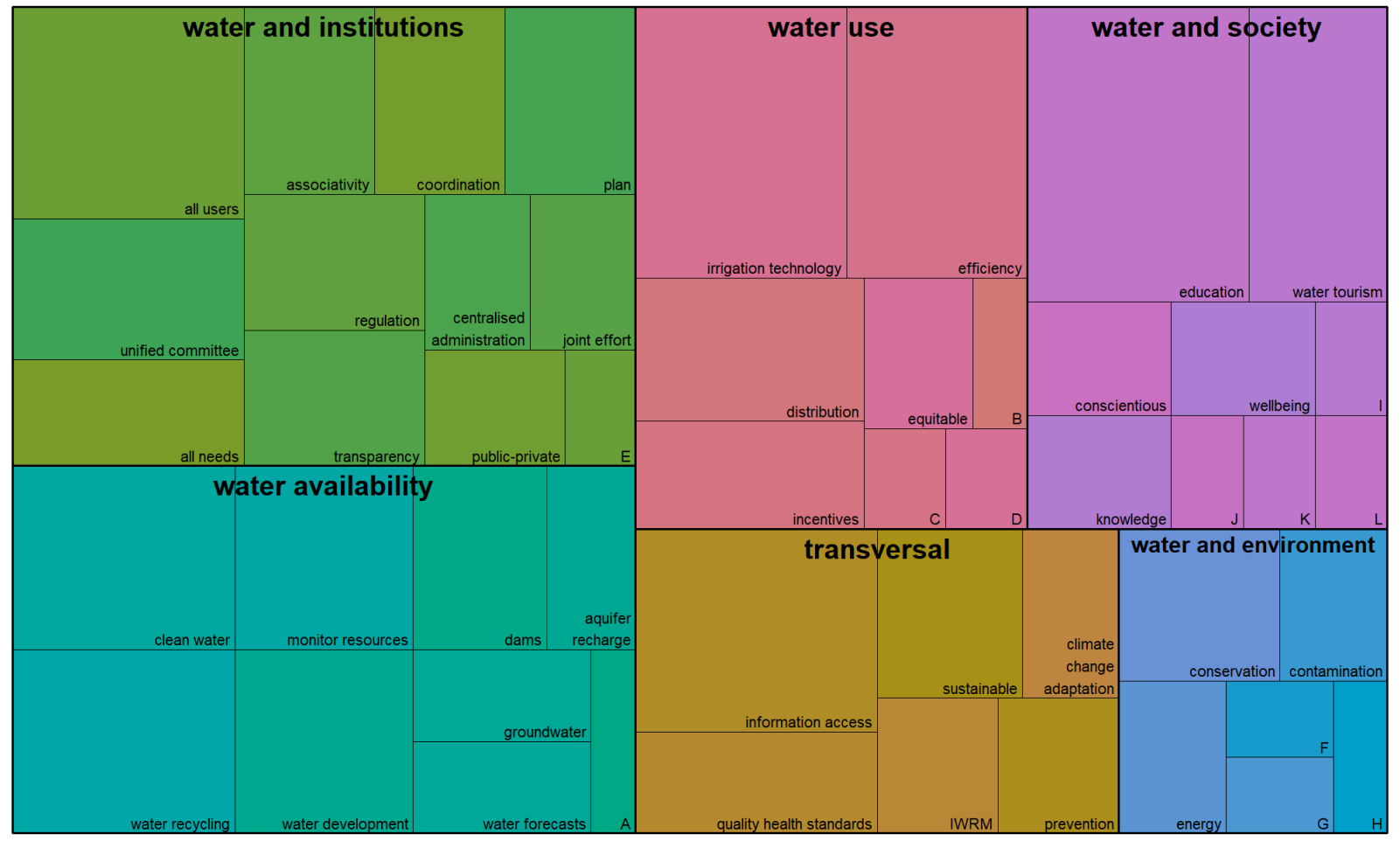

Figure 5. Treemap identifying most recurrent topics raised by stakeholders of circle $C$ at initial extended participatory workshops. Size reflects the proportion of mentions by stakeholders. Note, A, meteorological stations; B, guaranteed use; C, reduce losses; D, accumulation; E, support; F, reforestation; G, solid waste management; $\mathrm{H}$, environmental services; I, professionalism; J, solidarity; $\mathrm{K}$, training; L, employment.

We further distilled these water-related dimensions and arrived at 21 specific topics that embedded stakeholders' shared vision in the RRB (Figure 6). Four specific topics were transversal over two or more of the five dimensions and were related to adaptation to climate change, responsible management of solid waste, information management and implementation of IWRM in the RRB. 


\begin{tabular}{|c|c|c|c|c|}
\hline $\begin{array}{c}\text { Water } \\
\text { availability }\end{array}$ & $\begin{array}{l}\text { Water } \\
\text { use }\end{array}$ & $\begin{array}{l}\text { Water and } \\
\text { institutions }\end{array}$ & $\begin{array}{l}\text { Water and } \\
\text { environment }\end{array}$ & $\begin{array}{l}\text { Water and } \\
\text { society }\end{array}$ \\
\hline $\begin{array}{l}\text { E1 Water bodies } \\
\text { comply with } \\
\text { quality standards } \\
\text { for water supply } \\
\text { E2 Managed Aquifer } \\
\text { Recharge (MAR) is } \\
\text { implemented } \\
\text { E3 Different water } \\
\text { sources are } \\
\text { explored and } \\
\text { utilised (e.g. water } \\
\text { reclamation, } \\
\text { rainfall harvesting, } \\
\text { desal plants, etc.) }\end{array}$ & $\begin{array}{l}\text { E6 Best technologies } \\
\text { are applied to } \\
\text { improve water } \\
\text { efficiencies } \\
\text { E7 Water consumption } \\
\text { is guaranteed to all } \\
\text { users, proportional } \\
\text { to current and } \\
\text { future water } \\
\text { availability } \\
\text { E8 Water } \\
\text { infrastructure is } \\
\text { designed to satisfy } \\
\text { multiple uses }\end{array}$ & $\begin{array}{l}\text { E9 A high degree of } \\
\text { trust and } \\
\text { collaboration } \\
\text { between water } \\
\text { users and } \\
\text { regulators is } \\
\text { achieved } \\
\text { E10 A basin } \\
\text { organization } \\
\text { (multi-stakeholder) } \\
\text { is operational } \\
\text { E11 Plans and } \\
\text { strategies to } \\
\text { address natural }\end{array}$ & $\begin{array}{l}\text { E14 Biodiversity of the } \\
\text { basin is protected } \\
\text { E15 Environmental } \\
\text { flows are } \\
\text { implemented and } \\
\text { met in all main } \\
\text { rivers of the basin } \\
\text { E16 Extraction of } \\
\text { aggregates is } \\
\text { regulated and } \\
\text { controlled to } \\
\text { protect river banks } \\
\text { and channels }\end{array}$ & $\begin{array}{l}\text { E18 Tourism } \\
\text { development is } \\
\text { done with care of } \\
\text { the environment } \\
\text { and water } \\
\text { resources } \\
\text { E19 Water resources } \\
\text { management is } \\
\text { integrated into } \\
\text { education plans }\end{array}$ \\
\hline $\begin{array}{l}\text { E4 Continuous water } \\
\text { forecasts are }\end{array}$ & & & $\begin{array}{l}\text { E17 Responsible manage } \\
\text { undertaken }\end{array}$ & nt of solid waste is \\
\hline $\begin{array}{l}\text { accessible for } \\
\text { water availability } \\
\text { estimates in the } \\
\text { short-and long- } \\
\text { term scales }\end{array}$ & & $\begin{array}{l}\text { droughts) are in } \\
\text { place } \\
\text { E12 Control of water } \\
\text { resources use is } \\
\text { implemented } \\
\text { effectively and }\end{array}$ & & \\
\hline \multicolumn{2}{|c|}{$\begin{array}{l}\text { E5 Water Resources are managed in consideration } \\
\text { of the need to adapt to climate change }\end{array}$} & $\begin{array}{l}\text { efficiently } \\
\text { E13 Land planning is } \\
\text { consistent with the } \\
\text { vision of the basin }\end{array}$ & & \\
\hline & $\begin{array}{l}\text { E20 Informatior } \\
\text { E21 Integ }\end{array}$ & tom & quality controls & \\
\hline
\end{tabular}

Figure 6. Description of the elements of the shared vision used in the SNA for the RRB.

\subsection{Social Network Analysis}

4.3.1. Relationships between Stakeholders: Collaboration Ties, Information Flows, and Financial Exchanges Networks

Figure 7 shows the networks for collaboration ties, information flows and financial exchanges for stakeholders of the circle (B) and those identified through snowball sampling. This figure includes both low- and high-frequency interactions. It is important to note these networks are not explicitly associated with any particular stage of the decision making process. For collaborative ties (Figure 7a), the symbol size is proportional to the degree centrality, thus reflecting the total number of connections with other stakeholders. In general, frequent connections are predominantly identified for stakeholders of the public sector whereas less frequent connectivity is observed for the private sector. CODELCO, a major copper mining company in the region, shows the largest degree centrality for the private sector. A citizen-public stakeholder not originally included in circle B (MESAS_AMB) and related to environmental monitoring and assessment shows many high-frequency connections with peripheral stakeholders. Other stakeholders (e.g., CODEPRA, AGRESAP and AGROSUPER) show a higher degree centrality associated with collaborative ties of low-frequency. Figure $7 \mathrm{~b}$ shows the network for information flows with symbol size proportional to the outdegree (number of outbound links). In this case, we observe a similar pattern to the collaboration network, with a group of stakeholders comprising the core of the network and other stakeholders located at the periphery. Isolates (stakeholders located at the periphery) however are less compared to the network for collaborative ties, thus suggesting more stakeholders acting as connecting bridges with peripheral stakeholders. Finally, Figure 7c shows the network for financial exchanges, where the symbol size is proportional to the outdegree. That is, larger symbols reflect donors and smaller symbols reflect fund recipients. This network shows predominantly less frequent interactions among stakeholders. Both private 
and public sectors show important donors (CODELCO and GORE, respectively), whereas fund recipients are mainly the academia/civil society sector (CODEPRA, CSIRO, AGRESAP and UOH) and the citizen-public stakeholder MESAS_AMB.
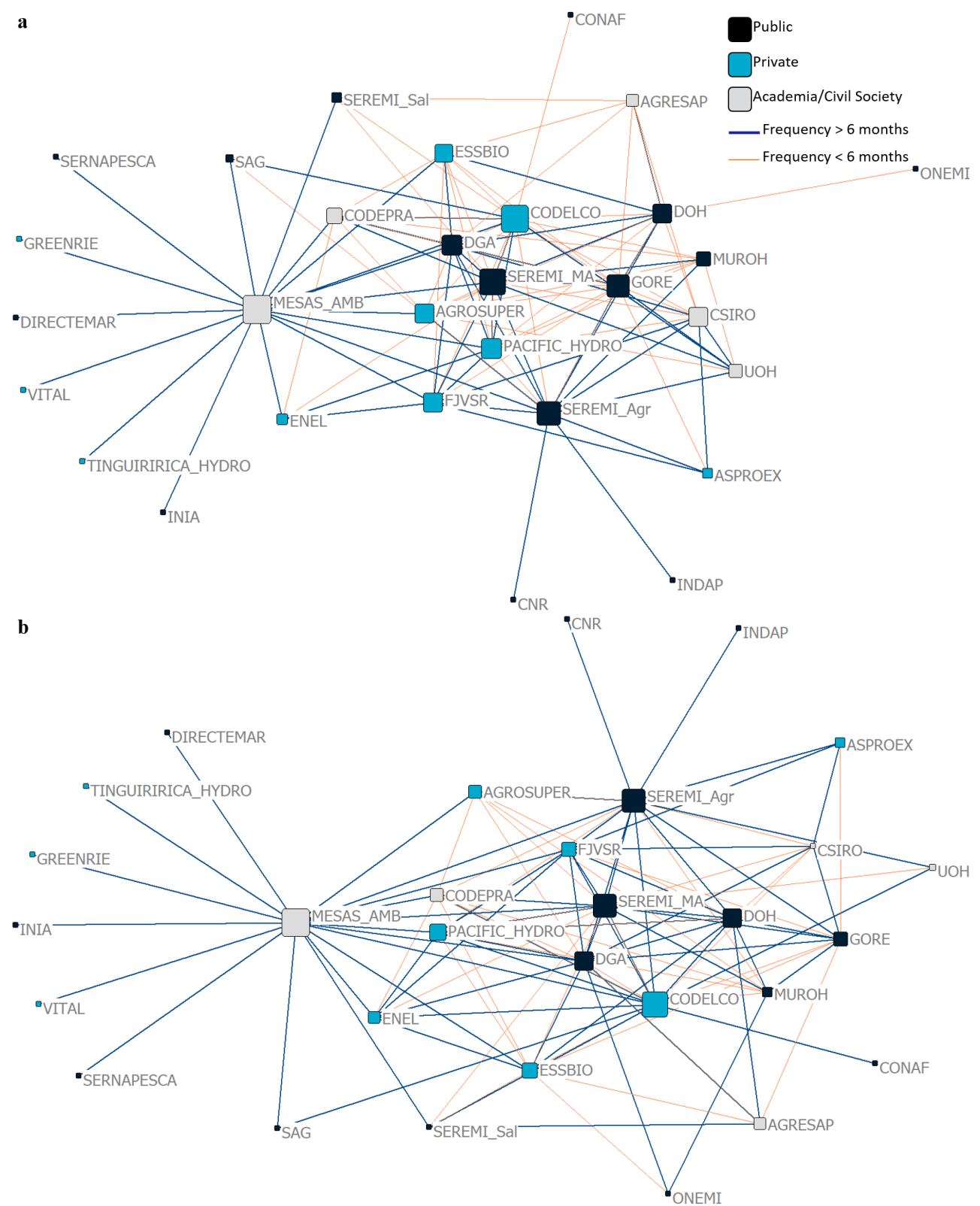

Figure 7. Cont. 


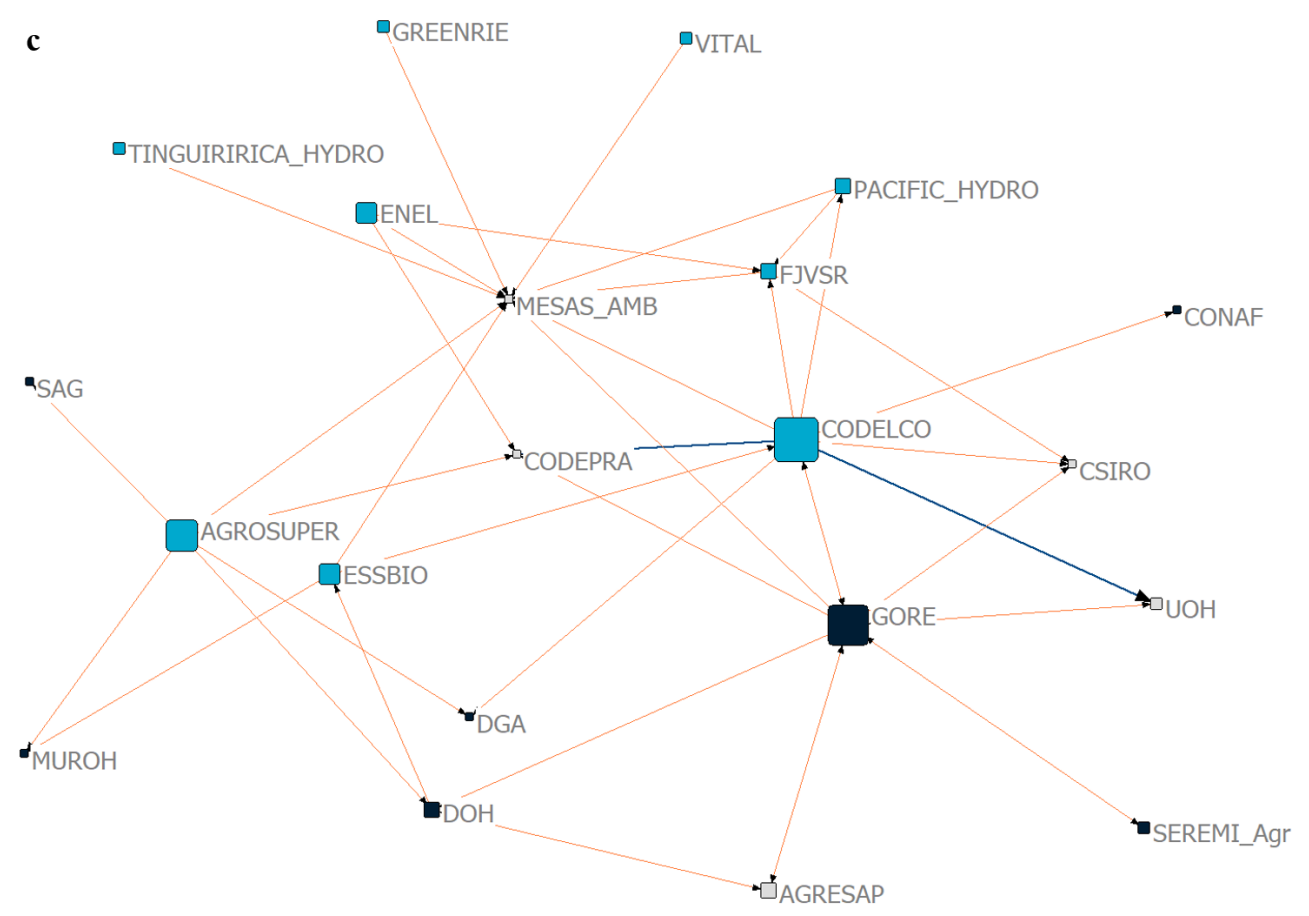

Figure 7. Network degree centrality for: (a) collaboration ties; (b) information flows; and (c) financial exchanges in the RRB.

The network densities for collaboration ties (0.23), information flows (0.23) and financial exchanges (0.09) indicate that only up to $23 \%$ of all potential connections are observed in practice. In sectoral terms, the private sector shows mostly low-frequency (greater than six months) interactions in comparison to those observed for the public sector. In terms of network-based centrality, expressed as the degree of variance (in percentage) from a perfectly star-shaped network of the same size, we observe low values between $12 \%$ and $35 \%$, thus indicating weak network-based centrality. Finally, most stakeholders' relationships across information flows and collaborative ties are reciprocal; however, the reciprocity of financial exchanges is less than 3\%, indicating most of the relationships in this network (Figure 7c) are unidirectional, with stakeholders acting either as donors or recipients of funds.

\subsubsection{Stakeholder-Based Centrality Metrics}

If we analyse stakeholder-based centrality metrics across the networks, some interesting patterns emerge. Table 2 shows centrality metrics calculated to assess the connectivity, proximity, control over material flows of attributes and relevance of stakeholders (see Table 1 for definitions). In this table, we delete 'isolates' (i.e., peripheral stakeholders) and add four additional stakeholders not included in circle B but deemed relevant for the analysis. 
Table 2. Centrality metrics for collaboration ties, information flows and financial exchanges networks for stakeholders in the RRB. DCent, Degree Centrality; CCent, Closeness Centrality; BCent, Betweenness Centrality; ECent, Eigenvector Centrality. Red coloured cells represent five bottom-ranked metric values, while green-coloured cells represent five top-ranked metric values.

\begin{tabular}{|c|c|c|c|c|c|c|c|c|c|c|c|c|}
\hline \multirow{2}{*}{ Stakeholder } & \multicolumn{4}{|c|}{ Collaboration } & \multicolumn{4}{|c|}{ Information } & \multicolumn{4}{|c|}{ Financial } \\
\hline & DCent & CCent & BCent & ECent & DCent & CCent & BCent & ECent & DCent & CCent & BCent & ECent \\
\hline AGRESAP & 0.207 & 0.345 & 0.005 & 0.120 & 0.172 & 0.392 & 0.002 & 0.106 & 0.069 & 0.266 & 0 & 0.095 \\
\hline AGROSUPER & 0.379 & 0.408 & 0.032 & 0.233 & 0.241 & 0.426 & 0.006 & 0.170 & 0.207 & 0.248 & 0.082 & 0.199 \\
\hline ASPROEX & 0.138 & 0.345 & 0 & 0.094 & 0.138 & 0.387 & 0 & 0.088 & 0 & 0.167 & 0 & 0 \\
\hline CODELCO & 0.586 & 0.460 & 0.133 & 0.322 & 0.586 & 0.518 & 0.148 & 0.319 & 0.345 & 0.322 & 0.124 & 0.446 \\
\hline CODEPRA & 0.310 & 0.372 & 0.011 & 0.198 & 0.310 & 0.439 & 0.008 & 0.211 & 0.138 & 0.299 & 0.022 & 0.219 \\
\hline CSIRO * & 0.379 & 0.200 & 0.017 & 0.234 & 0.276 & 0.250 & 0.004 & 0.190 & 0.103 & 0.167 & 0.002 & 0.209 \\
\hline DGA & 0.414 & 0.397 & 0.027 & 0.264 & 0.517 & 0.475 & 0.066 & 0.308 & 0.069 & 0.167 & 0.005 & 0.122 \\
\hline $\mathrm{DOH}$ & 0.379 & 0.377 & 0.076 & 0.232 & 0.414 & 0.475 & 0.017 & 0.263 & 0.138 & 0.261 & 0.021 & 0.170 \\
\hline ENEL & 0.172 & 0.322 & 0.001 & 0.115 & 0.276 & 0.420 & 0.001 & 0.197 & 0.103 & 0.176 & 0.004 & 0.183 \\
\hline ESSBIO & 0.345 & 0.349 & 0.019 & 0.225 & 0.414 & 0.420 & 0.044 & 0.242 & 0.172 & 0.181 & 0.036 & 0.274 \\
\hline FJVSR & 0.379 & 0.382 & 0.029 & 0.240 & 0.379 & 0.433 & 0.029 & 0.249 & 0.207 & 0.172 & 0.018 & 0.331 \\
\hline GORE & 0.483 & 0.392 & 0.036 & 0.282 & 0.379 & 0.446 & 0.022 & 0.235 & 0.276 & 0.290 & 0.110 & 0.333 \\
\hline MESAS AMB * & 0.621 & 0.690 & 0.408 & 0.250 & 0.621 & 0.725 & 0.409 & 0.262 & 0.345 & 0.330 & 0.182 & 0.420 \\
\hline MUROH & 0.276 & 0.354 & 0.003 & 0.187 & 0.310 & 0.392 & 0.016 & 0.194 & 0.069 & 0.167 & 0.002 & 0.089 \\
\hline PACIFIC HYDRO & 0.414 & 0.420 & 0.027 & 0.266 & 0.345 & 0.460 & 0.009 & 0.242 & 0.103 & 0.176 & 0 & 0.226 \\
\hline $\mathrm{SAG}^{*}$ & 0.103 & 0.200 & 0 & 0.073 & 0.069 & 0.250 & 0 & 0.053 & 0.034 & 0.167 & 0 & 0.038 \\
\hline SEREMI Agr & 0.517 & 0.433 & 0.177 & 0.283 & 0.552 & 0.500 & 0.192 & 0.292 & 0.034 & 0.246 & 0 & 0.063 \\
\hline SEREMI MA & 0.552 & 0.426 & 0.057 & 0.324 & 0.552 & 0.500 & 0.055 & 0.327 & 0 & 0.167 & 0 & 0 \\
\hline SEREMI Sal * & 0.138 & 0.200 & 0.008 & 0.091 & 0.172 & 0.250 & 0.008 & 0.115 & 0 & 0.167 & 0 & 0 \\
\hline UOH & 0.241 & 0.367 & 0.001 & 0.168 & 0.103 & 0.367 & 0 & 0.086 & 0.069 & 0.246 & 0 & 0.147 \\
\hline
\end{tabular}

Across all stakeholders, CODELCO and MESAS_AMB emerge as top-ranked in all three CWG-enabling networks. MESAS_AMB, however, shows a comparatively lower metric for relevance, suggesting mostly connections to peripheral stakeholders. Organisations related to environmental and agriculture regulation (SEREMI_MA and SEREMI_Agr) are top-ranked in both collaboration ties and information flows, but bottom-ranked in most centrality metrics in the financial exchanges network. This suggests these stakeholders have secondary roles as donors or recipients of funds but have major roles in collaborative ties and information flows. The Regional Water Authority (DGA) emerges as top-ranked in the information flows network given its role as the main hydrological data custodian in the RRB, whereas the Regional Government (GORE) is top-ranked in financial exchanges due to its role as the major project sponsor in the RRB. Other stakeholders are relevant for individual centrality metrics within specific networks only, thus highlighting the variable roles stakeholders might have in the three CWG-enabling networks analysed.

Bottom-ranked stakeholders across all networks include the regional Farmers' association (ASPROEX) and regional government institutions related to agriculture/livestock regulation and public health (SAG and SEREMI_Sal). These last institutions are currently not included in circle B and results show that there may be little benefit from including these stakeholders as permanent members of this cohort. Interestingly, two stakeholders of the academia/civil society sector (UOH and AGRESAP) also show low centrality metrics in the collaboration ties and information flows networks, suggesting they have secondary roles in these networks.

\subsubsection{Interest-Influence Map Versus Stakeholder-Based Centrality Metrics}

When comparing the centrality metrics in Table 2 and the interest-influence map in Figure 4, some patterns can be identified. In general, top-ranked stakeholders across different centrality metrics are mostly located in the high-influence-high-interest quadrant, whereas, for those stakeholders located around the central part of Figure 4 (e.g., ENEL, ESSBIO and PACIFIC HYDRO), centrality metrics generally agree with their relative location. Interestingly, weaker connectivity, proximity and relevance in the collaboration ties and information flow networks would suggest a move towards the quadrant of low-influence-low-interest in Figure 4 for some stakeholders (e.g., UOH and MUROH). At the same time, 
some stakeholders perceived as having a high influence and interest in Figure 4 are bottom-ranked in centrality metrics (e.g., ASPROEX and AGRESAP), suggesting disagreement between both techniques (SNA and SA).

In terms of relative stakeholders' positions, CODELCO holds a more influential position across all CWG-enabling networks compared to other stakeholders (e.g., FJVSR, DGA), whereas centrality metrics for ASPROEX contradicts its higher relative location in the high-influence-high-interest quadrant of Figure 4.

Although not included here, a partition-based core-periphery analysis [70] indicates that the following stakeholders are persistently located in the periphery of the CWG-enabling networks: ASPROEX and ENEL (private sector), MUROH (public sector) and AGRESAP and UOH (academia/civil society sector).

\subsubsection{Stakeholders' Influence on the Elements of The Vision}

Figure 8 shows a two-mode (stakeholder-element of the vision) network analysis describing the influence stakeholders have in achieving the 21 elements of the shared vision defined for the RRB (Figure 6). In this figure, two nodes are close to each other if their geodesic distance is short [69]. Therefore, stakeholders are close to each other if they declare some level of influence on similar elements of the vision, and elements of the vision are clustered if they are influenced by a similar stakeholder cohort.

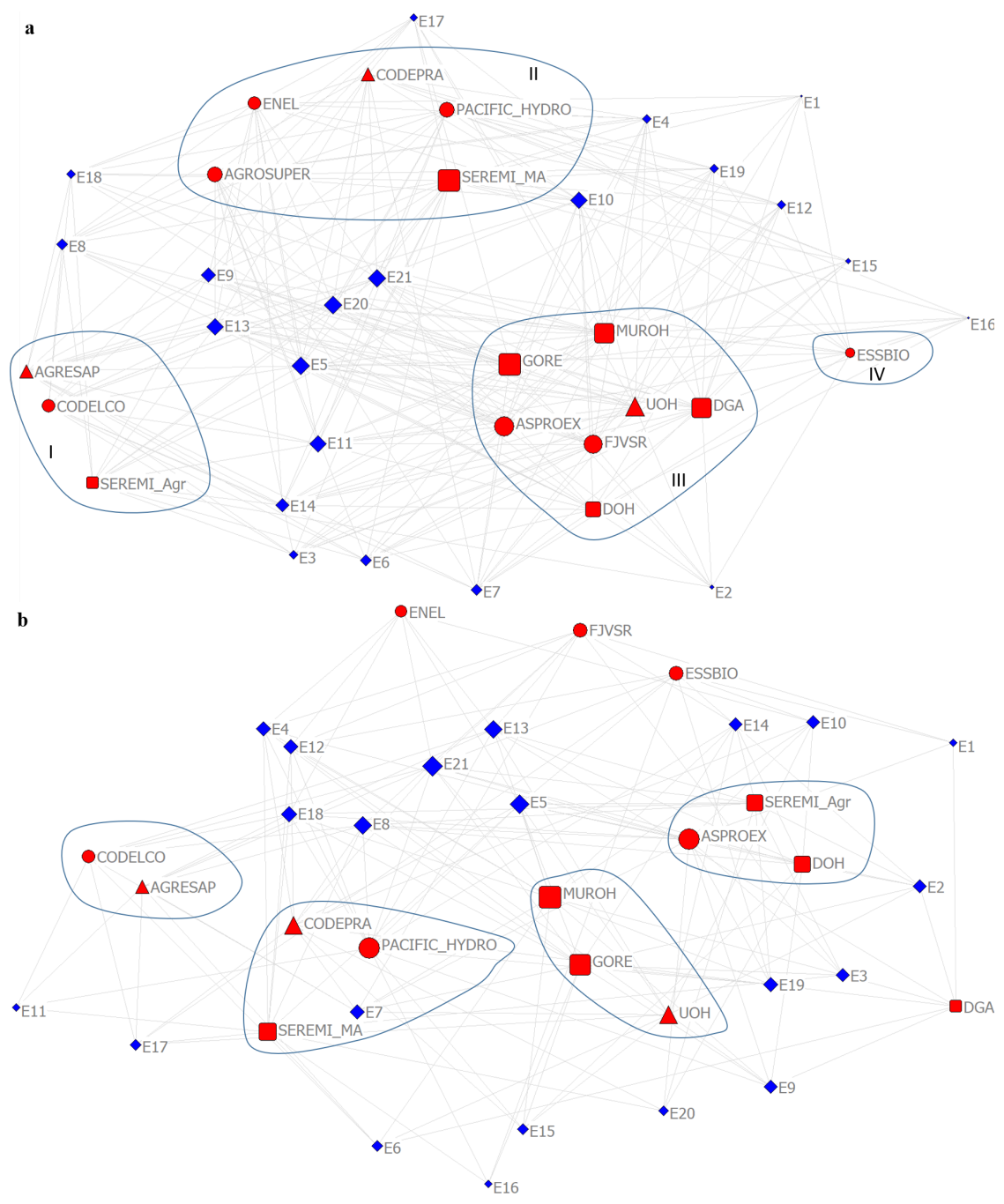

Figure 8. Cont. 


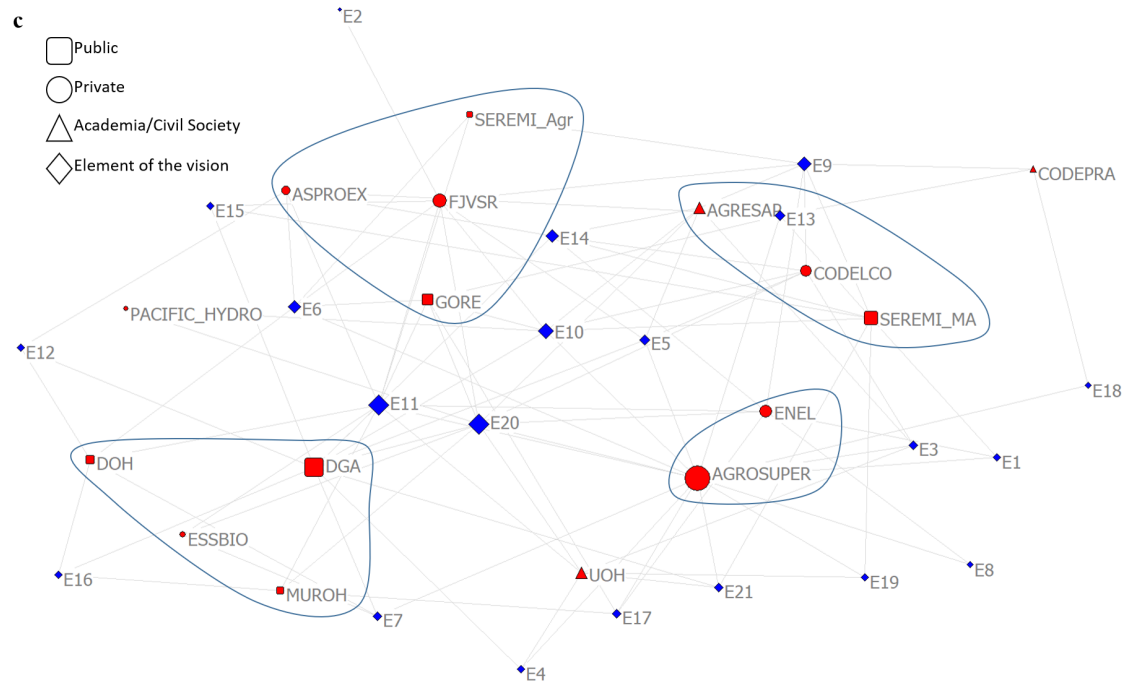

Figure 8. Network of stakeholders' influence in achieving elements of the shared vision (Figure 6) developed for the RRB: (a) all levels of influence; (b) low level of influence; and (c) high level of influence.

Figure 8a shows a clear clustering of stakeholders with at least four groupings identified. Except for Group IV, all clusters show members from all three sectors (public, private and civil society) thus suggesting transversal heterogeneity for the influence on common elements of the shared vision. Interestingly, the low-influence network is dominated by public and academia/civil society stakeholders (Figure 8b), whereas the high-influence network is more heterogeneous (Figure 8c) in terms of dominant sectors.

The least influenced elements of the vision (in terms of the degree of connections) by stakeholders (Figure 8a) are related to water quality compliance (E1), implementation of Managed Aquifer Recharge (E2), implementation of environmental flows across the basin (E15) and regulation of extraction of aggregates from river banks (E16). The clustering of Figure 8a shows that there is a central group related to water and institutions, IWRM implementation, information management and adaptation to climate change (see Figure 6) that is influenced transversally for most stakeholders in the RRB. Similarly, stakeholders indicate a high-influence on aspects related to the implementation of a basin organisation (E10), strategies to address natural risks and disasters (E11) and information management (E20) (Figure 8c).

Figure 9 shows a reclassification of the two-mode (stakeholder-elements of the vision) network into one-mode networks for stakeholders and elements of the vision. A multidimensional scaling (MDS) analysis was applied to the graph using the Jaccard similarity index as a metric [71]. The Jaccard index shows the percentage of coincidence among stakeholders for the elements of the vision over which they have some degree of influence. Figure 9a,b show the networks for low- and high-influence on the vision. CODELCO and AGRESAP have been manually relocated as they overlapped with a Jaccard index equal to 1, meaning the stakeholders shared the same level of influence over the same elements of the vision. 


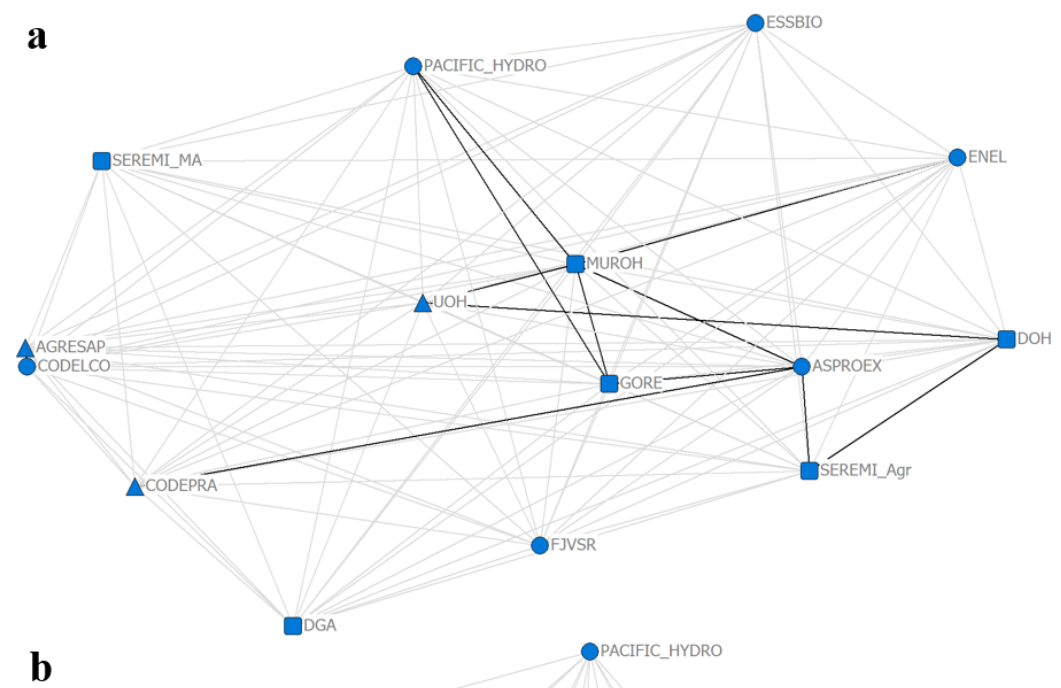

b

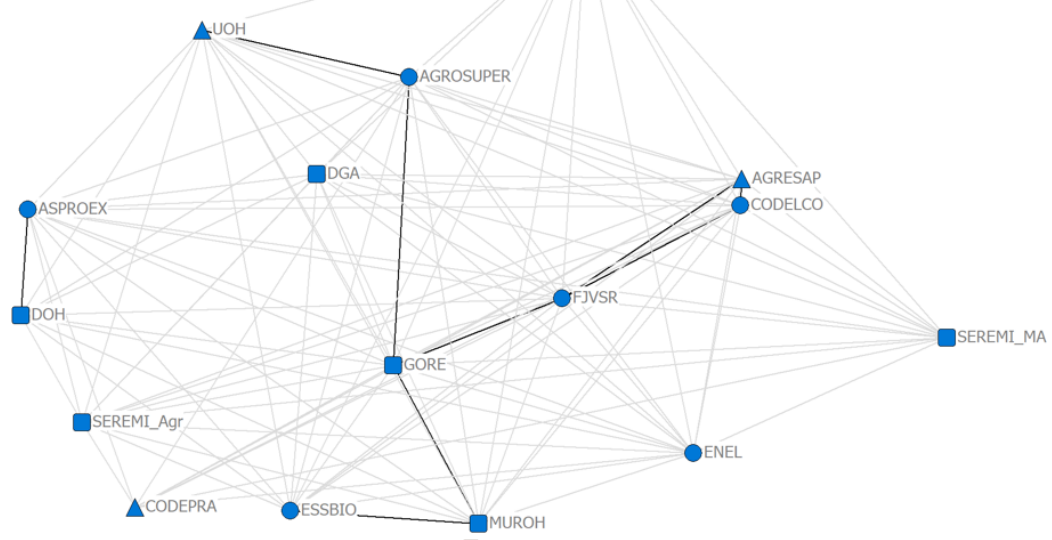

c
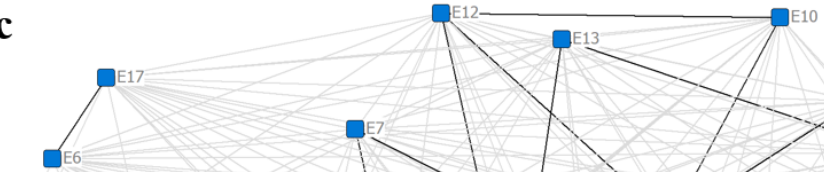

E1:

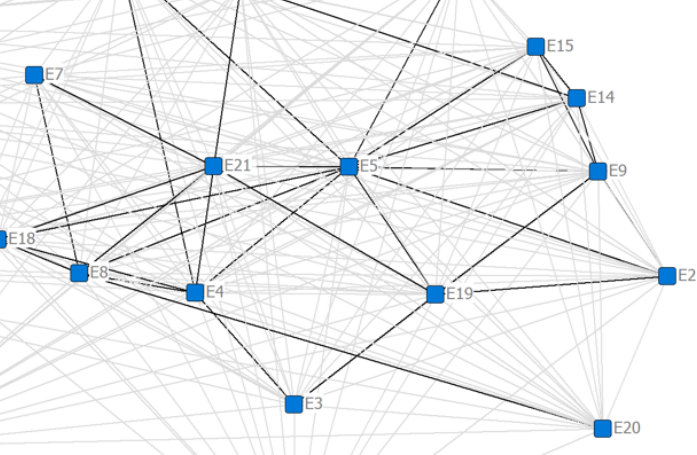

E16

DE1

Figure 9. Cont. 


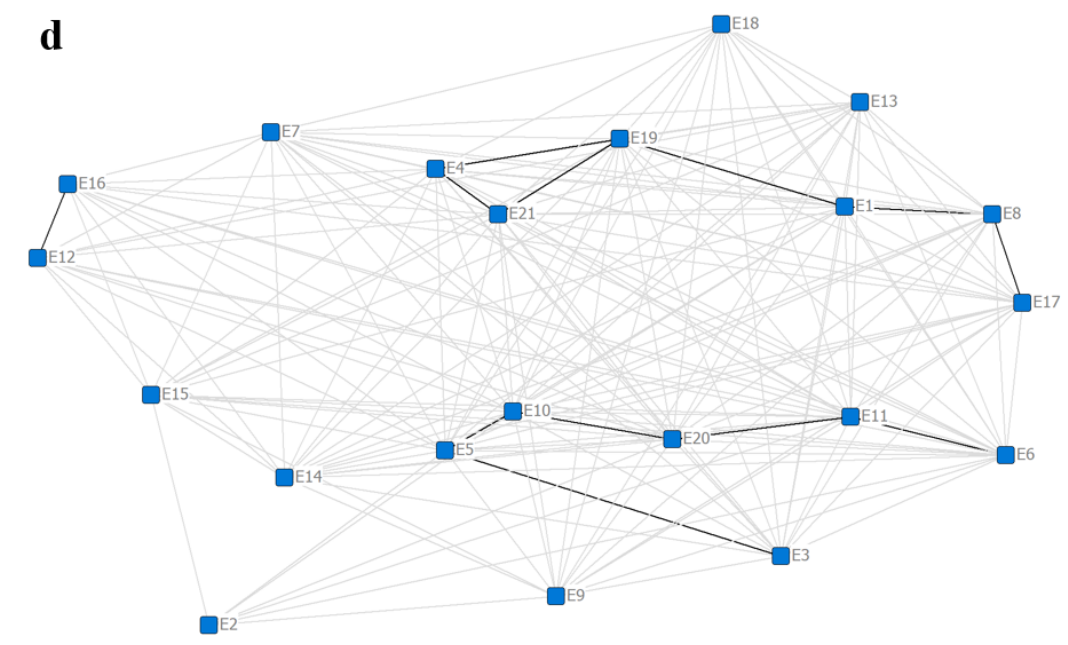

Figure 9. Jaccard similarities for both low $(\mathbf{a}, \mathbf{c})$ and high $(\mathbf{b}, \mathbf{d})$ influence networks for stakeholders $(\mathbf{a}, \mathbf{b})$ and elements of the shared vision (c,d) for the RRB. Light grey ties show Jaccard similarities below 0.5. Black ties show Jaccard similarities greater or equal than 0.5 .

In general, stakeholders show a weak similarity (below 50\%) over which common elements they have an influence on, with just a few stakeholders showing similarities greater than $50 \%$ (i.e., they coincide on their influence over at least half of the same elements of the shared vision) (Figure 9a). Grouping suggests that stakeholders belonging to private, public and civil society/academia sectors show agreement on declaring a low-influence to achieve similar elements of the shared vision. Interestingly, the Regional Water Authority (DGA) shows a high-influence on elements of the vision (Figure 8c); however, it does not strongly coincide with other stakeholders in the RRB (Figure 9b). In terms of network-based connectivity, it is interesting to note the bridging role of FJVSR in the high-influence network between public, private and academia/civil society sectors (Figure 9 b).

Finally, similarity among aspects of the vision influenced by stakeholders is more relevant in the low-influence network (Figure 9c) compared to the high-influence network (Figure 9d). In the latter, however, a clear grouping of similarities greater than $50 \%$ is observed, where water and institutions and water availability are followed by water use, and water and society.

\section{Discussion}

\subsection{Stakeholder Participation, Interests and Collaborative Process}

Existing organisations related to water management/planning/use were brought together for the first time in the RRB under a participatory process approach. The results of the PP show the development of new understanding about basin-scale processes, knowledge sharing, increasing awareness of stakeholders' roles and functions across CWG-enabling networks, evidence of stakeholders' interdependence and willingness to collaborate and discuss beyond institutional/legal mandate. The co-construction of the shared vision helped create consensus and awareness regarding water-related challenges and promoted a systemic view of the RRB under the CWG umbrella. Therefore, it can be argued that we contributed to increasing stakeholders' interdependence and awareness about their water-related roles in the basin: both stakeholders' interdependence and awareness are key features of social learning [10,72]. In particular, through numerous participatory instances, we witnessed the fostering of trust among stakeholders, increased commitment to participate and the willingness of taking coordinated action to tackle immediate and future water-related challenges. Enhanced trust and stakeholder empowerment were identified as two (among others) outcomes of social learning by Reed et al. [73]. We can therefore argue that the PP has 
been successful in underpinning the collaborative process described by Ansell and Gash [13] (Figure 2), with social learning about water-related challenges and CWG (more generally) as an intermediate material outcome. We concur, however, with Sayles and Baggio [74] that collaboration in itself is not a 'silver bullet' to solve wicked water-related problems: it further needs a proper account of external drivers (e.g., starting conditions, facilitative leadership and institutional design) for successful outcomes.

In line with Prell et al. [32], we built on stakeholders' views and perceptions to distil important elements of the shared vision in the RRB. The dimension 'water and institutions' concentrated stakeholders' interests, where the creation of an organisation coordinating water governance efforts was prioritised. The dichotomy of a highly relevant aspect for stakeholders (i.e., a need for a coordinating organism for water governance) and the absence of a leading organisation implementing water governance in the RRB reflects an important implementation challenge for CWG in practice. Budds [58] and Gálvez et al. [37] discussed this challenge under the lens of competitive vs collaborative behaviour for water management, whereas Prieto [57] highlighted the contradiction of communitarian water management and power asymmetries under the current water management framework in Chile. We acknowledge therefore that the 'institutional design' where CWG sits will set the operational context and may play a role in conditioning the success or failure of CWG (e.g., [75]). As mentioned before, this external driver of the CWG framework (see Figure 2) was not addressed in this work as it is the subject of separate research for the RRB.

\subsection{Network-Based Metrics and Implications for CWG}

Network-based metrics indicate that all three CWG-enabling networks were weakly connected. This suggests that there is a large potential to further promote communication, information sharing and knowledge generation $[30,36]$ to enable CWG in the RRB. Early participatory workshops showed low levels of prior stakeholder interaction and a lack of network identity, thus confirming a limited performance in terms of adaptive capacity for collaborative water governance [27].

For both the collaboration ties and information flows networks, two levels of frequency were observed. As highlighted by Prell et al. [31], novel ideas travel best through less frequent communication (weak ties), whereas a redundancy of information is usually observed for more frequent communication. It can therefore be argued that, by experiencing high- and low-frequency interactions among stakeholders, circle $B$ is in a privileged position for exchange of information and discussion of innovative ideas without the need to include a large cohort of stakeholders.

Centralisation values (up to 35\%) indicate weakly centralised network structures across the three CWG-enabling networks. Research shows that strongly centralised networks are effective in building initial support for collective action but show disadvantages for long-term water planning and problem-solving [31,36]. It can then be argued that networks for information flows and collaboration ties in the RRB show advantages towards the achievement of long-term water planning goals for CWG but might face difficulties to initiate collective action against water-related challenges (e.g., climate change impacts). This situation emphasises the role that individual stakeholders might have as brokers in their corresponding networks to facilitate or hinder CWG (see, e.g., [76,77]).

The network for financial exchanges is characterised by the lowest density, centralisation, reciprocity and frequency of ties among stakeholders. This network is therefore particularly vulnerable to fragmentation of connecting stakeholders and possibly not a suitable environment for fostering trust across stakeholders in the CWG context [27,31].

Across all networks analysed, we observed a diverse group of stakeholders from public, private and academia/civil society sectors, with connections beyond specific sectors and declaring influence on diverse elements of the shared vision for the RRB. Core-periphery modelling identified stakeholders from across all three sectors as part of the core structure of the networks, thus showing no bias towards any specific 
sector. Sandström and Rova [78] suggested both features (i.e., stakeholders' diversity and cross-boundary exchange) as key properties describing 'network heterogeneity'. At the same time, they described 'network closure' (i.e., network structures that are well integrated either through many connections or bridging actors) as a key concept related to the adaptive capacity of social networks. Both network heterogeneity and closure (empirically expressed by the network density and centrality) are described as fundamental properties to enable adaptive capacity for natural resources management [78]. It can then be argued that heterogeneity is high across the CWG-enabling networks in the RRB, suggesting high potential for innovative problem solving [76], whereas network closure is the weakest attribute, thus jeopardising the adaptive capacity of stakeholders in the RRB [78].

\subsection{Stakeholders' Roles and Influence on the Shared Vision for the RRB}

The results suggest that different stakeholders of circle B perform key roles in specific networks while potentially having secondary roles in other networks. This indicates that the relevance of centrality metrics to analyse stakeholders' roles must be explored in terms of alternative sources of influence across different attributes. These results are in full agreement with the findings by Prell et al. [31]. Thus, whilst some stakeholders might have a relevant role in just one of the three CWG-enabling networks, this relevance might warrant participation in CWG initiatives.

Most of the stakeholders of circle B (see Figure 3) are found in the core of at least two CWG-enabling networks. The exceptions are ASPROEX and ENEL (private sector), MUROH (public sector) and AGRESAP and $\mathrm{UOH}$ (academia/civil society), which occupy mainly secondary roles. Therefore, a thorough assessment of the connections, interests and influence of these stakeholders needs to be undertaken in order to consolidate and strengthen their participation in any future endeavours aiming at CWG in the RRB.

It is worth noting that MESAS_AMB (citizen-public organisation related to environmental monitoring and assessment not originally included in circle B) is top-ranked in most centrality metrics across all CWG-enabling networks. Interestingly, MESAS_AMB shows a brokerage role (high betweenness centrality [76,77]) in all three networks, therefore connecting otherwise unconnected parts of the CWG-enabling networks. This highlights its potential role in mobilising and diffusing information/data, collaboration efforts and financial resources to the larger network [31,43]. According to Bodin et al. [76] and Vignola et al. [77], this would grant MESAS_AMB a critical role in these networks for CWG in the RRB.

Our results show partial disagreement between stakeholders perceived as having a high influence and interest, whilst being bottom-ranked in centrality metrics and having peripheral roles in the networks analysed. We do not see this as a disadvantage but rather as deeper complementary insights into stakeholders' relationships and roles in these networks. Several authors have shown the value of complementing quantitative and qualitative techniques to decipher stakeholders' roles and functions across different disciplines [31,43,79-81].

Aspects of the vision related to water and environment (water quality compliance and environmental flows) were identified as the least influenced by stakeholders, whereas water and institutions and water availability are the most influenced. This distinction might be related to the current situation in the RRB, where persistent droughts have shifted the discussion among stakeholders towards water availability/use rather than water quality compliance and environmental regulation. One path to address this potential issue would be to perform SNA for different periods as in [27].

\subsection{Advancing Collaborative Water Governance and Addressing Implementation Challenges}

The cohort of stakeholders belonging to circle B represents an excellent first-iteration to create an organism leading and initiating a collaborative water governance instance in the RRB. Additional stakeholders suggested through the participatory approach however show limited added value in terms 
of promoting CWG-enabling networks. The exception to this is the inclusion of the citizen-public organisation MESAS_AMB, which showed a valuable brokerage and connecting role in the networks analysed. This relevance however remains to be seen given the dichotomy between the current role of MESAS_AMB (environmental monitoring and assessment) and the low priority and influence stakeholders have indicated for the 'water and environment' dimension of the shared vision in the RRB.

Basin-wide CWG-enabling networks in the RRB have shown that much need to be done to strengthen the starting conditions of the framework underpinning CWG in the basin. In particular, the connectivity among stakeholders (network densities) needs to be increased to minimise potential power, resources and knowledge imbalances across the RRB (see, e.g., $[16,26,27]$ ). Although a history of collaborative ties and information flow is present in the RRB, centrality metrics indicate that increasing density/connectivity of these networks would strengthen these aspects and thus provide a more solid underpinning to initiate CWG in the basin. In terms of the incentives/constraints for participation, the financial exchanges network suggests resources are distributed to a limited cohort of stakeholders with very low reciprocity and density, thus with a limited number of stakeholders acting as donors. The latter makes efforts to formally fund CWG initiatives particularly vulnerable to stakeholder fragmentation, where financial incentives for participation do not reach the full extent of circle B.

In terms of facilitative leadership, we identified stakeholders across the public, private and academia/civil society sectors holding prominent functions across the CWG-enabling networks: bridging roles connecting peripheral stakeholders (MESAS_AMB), information gatekeepers and data custodians (DGA), proximal roles for the relevance of collaboration ties (FJVSR and SEREMI MA/Agr) and control over material flows of attributes (CODELCO, GORE and AGROSUPER). This leadership however is not currently formalised along with a basin organisation in the RRB. This is probably one of the major implementation challenges to CWG in order to overcome the lack of coordination among stakeholders and conflict resolution needs $[16,26]$. At the same time, we identified a cohort of stakeholders persistently located in the periphery of the CWG-enabling networks holding secondary roles, mostly composed of public and academia/civil society stakeholders. An important CWG implementation challenge would be to increase the connectivity and centrality of these stakeholders to grow mobilisation of resources and information and promote communication and collaboration [27]. A potential strategy would be to create thematic groups guided by the influence/interest level on common elements of the shared vision (e.g., CODELCO and AGRESAP).

We acknowledge that not only the structure of social networks might change with time but also the contents and intensities of what is transferred through them [30]. Therefore, we do not see CWG implementation challenges in the RRB as static obstacles, but rather as evolving barriers that need to be tackled by increasing adaptive capacity through time (see, e.g., [24,27]).

\section{Conclusions}

In this work, we demonstrated the value of complementing stakeholder analysis, social network analysis and participatory processes under the umbrella of a theoretical collaborative water governance (CWG) framework. Deeper insights about stakeholders' relationships and common interests and the identification of their specific roles in basin-wide CWG-enabling networks (collaboration ties, information flows and financial exchanges) were gained.

A proposed cohort of stakeholders (circle B + MESAS_AMB) was identified as an excellent first-iteration to concentrate efforts formalising a leading organisation to implement CWG in the RRB. On the other hand, a subgroup of stakeholders belonging to circle B was consistently in the periphery of networks occupying secondary roles and showing a limited influence on specific elements of the shared vision. These stakeholders thus need to be enabled for better connectivity, proximity and relevance 
across the CWG-enabling networks. To enable these peripheral stakeholders, common interests grouping derived from SNA can be used to improve connectivity and proximity through working groups or focused discussions. This, however, will require a careful balance between the 'homophily effect' and preserving heterogeneity across networks.

Network heterogeneity is high in the RRB, whereas network closure is relatively weak. This suggests the proposed cohort of stakeholders is privileged in terms of sharing innovative ideas for CWG, probably experiencing a weak adaptive capacity to potential water management challenges (e.g., climate change impacts) across the networks analysed.

A clear gap between the current operational framework to water management in the RRB and stakeholders' ambitions in terms of 'water and institutions' was identified. Current institutional/legislative frameworks act as a boundary condition thus potentially hindering advancement towards CWG in the RRB. One way forward would be organising the proposed cohort of stakeholders as a formal basin organisation to facilitate CWG and enable achievement of the shared vision.

By implementing the methodological framework, we facilitated social learning, fostered trust among stakeholders and mobilised efforts in the appropriate direction to implement CWG in practice in the contentious RRB.

Author Contributions: Conceptualisation, R.R. and G.B.; methodology, R.R., G.B. and V.G.; formal analysis, R.R., G.B., V.G. and G.C.; investigation, R.R. and G.B.; data curation, G.B. and V.G.; writing-original draft preparation, R.R. and G.B.; writing-review and editing, R.R., E.C. and G.C.; supervision, E.C.; and funding acquisition, R.R., G.B. and E.C. All authors have read and agreed to the published version of the manuscript.

Funding: This research was funded by the Regional Government of O'Higgins grant number IDI: 30427997-0.

Acknowledgments: We thank the Federación de Juntas de Vigilancia de la Sexta Región (FJVSR) and Dirección Regional de Aguas (DGA), Región de O'Higgins, for continuous support throughout this research. The authors thank all participating stakeholders and institutions who have contributed time and efforts to provide local knowledge and expertise. Special thanks are given to Hernán Blanco, Graciela Correa, Juan Carlos Castilla-Rho and Mauricio Caroca for contributions to this research.

Conflicts of Interest: The authors declare no conflict of interest. The funders had no role in the design of the study; in the collection, analyses, or interpretation of data; in the writing of the manuscript, or in the decision to publish the results.

\section{References}

1. Basco-Carrera, L.; van Beek, E.; Jonoski, A.; Benítez-Ávila, C.; Guntoro, F.P. Collaborative Modelling for Informed Decision Making and Inclusive Water Development. Water Resour. Manag. 2017, 31, 2611-2625. [CrossRef]

2. Bouwer, H. Integrated water management: Emerging issues and challenges. Agric. Water Manag. 2000, 45, 217-228. [CrossRef]

3. United Nations-Water. Coping with water scarcity. A strategic issue and priority for system-wide action. In UN-Water Thematic Initiatives; Technical Report; United Nations: New York, NY, USA, 2006.

4. World Economic Forum. Global Risks 2019: Insight Report, 14th ed.; World Economic Forum: Geneva, Switzerland, 2019.

5. GWP. Integrated Water Resources Management; Global Water Partnership: Stockholm, Sweden, 2000.

6. OECD. Water Governance in OECD Countries: A Multi-Level Approach, OECD Studies on Water, ed.; OECD: Paris, France, 2011.

7. Lautze, J.; de Silva, S.; Giordano, M.; Sanford, L. Putting the cart before the horse: Water governance and IWRM. Nat. Resour. Forum 2011, 35, 1-8. [CrossRef]

8. Jiménez, A.; Saikia, P.; Giné, R.; Avello, P.; Leten, J.; Lymer, B.L.; Schneider, K.; Ward, R. Unpacking Water Governance: A Framework for Practitioners. Water 2020, 12, 827. [CrossRef]

9. OECD. OECD Principles on Water Governance; Technical Report; OECD: Paris, France, 2015.

10. Pahl-Wostl, C. An Evolutionary Perspective on Water Governance: From Understanding to Transformation. Water Resour. Manag. 2017, 31, 2917-2932. [CrossRef] 
11. Cook, C.; Bakker, K. Water security: Debating an emerging paradigm. Glob. Environ. Chang. 2012, 22, 94-102. [CrossRef]

12. Zwarteveen, M.; Kemerink-Seyoum, J.S.; Kooy, M.; Evers, J.; Guerrero, T.A.; Batubara, B.; Biza, A.; Boakye-Ansah, A.; Faber, S.; Flamini, A.C.; et al. Engaging with the politics of water governance. Wiley Interdiscip. Rev. Water 2017, 4, e1245. [CrossRef]

13. Ansell, C.; Gash, A. Collaborative Governance in Theory and Practice. J. Public Adm. Res. Theory 2008, 18, 543-571. [CrossRef]

14. Emerson, K.; Nabatchi, T.; Balogh, S. An Integrative Framework for Collaborative Governance. J. Public Adm. Res. Theory 2012, 22, 1-29. [CrossRef]

15. Holley, C. Crafting Collaborative Governance: Water Resources, California's Delta Plan, and Audited Self-Management in New Zealand. Environ. Law Rep. News Anal. 2015, 45, 1-14.

16. Harrington, C. The political ontology of collaborative water governance. Water Int. 2017, 42, 254-270. [CrossRef]

17. Marín, A.; Berkes, F. Network approach for understanding small-scale fisheries governance: The case of the Chilean coastal co-management system. Mar. Policy 2010, 34, 851-858. [CrossRef]

18. Connick, S.; Innes, J.E. Outcomes of Collaborative Water Policy Making: Applying Complexity Thinking to Evaluation. J. Environ. Plan. Manag. 2003, 46, 177-197. [CrossRef]

19. Sabatier, P.; Focht, W.; Lubell, M.; Trachtenberg, Z.; Vedlitz, A.; Matlock, M. Swimming Upstream: Collaborative Approaches to Watershed Management; MIT PR: Cambridge, MA, USA, 2005.

20. Butterworth, J.; Warner, J.; Moriarty, P.; Smits, S.; Batchelor, C. Finding practical approaches to integrated water resources management. Water Altern. 2010, 3, 68-81.

21. Moriarty, P.; Batchelor, C.; Laban, P.; Fahmy, H. Developing a practical approach to 'light IWRM' in the middle east. Water Altern. 2010, 3, 122-136.

22. Smith, J.L. A critical appreciation of the "bottom-up" approach to sustainable water management: Embracing complexity rather than desirability. Local Environ. 2008, 13, 353-366. [CrossRef]

23. Agrawal, A.; Gibson, C.C. Enchantment and Disenchantment: The Role of Community in Natural Resource Conservation. World Dev. 1999, 27, 629-649. [CrossRef]

24. Ogada, J.O.; Krhoda, G.O.; Veen, A.V.D.; Marani, M.; van Oel, P.R. Managing resources through stakeholder networks: Collaborative water governance for Lake Naivasha basin, Kenya. Water Int. 2017, 42, 271-290. [CrossRef]

25. Ananda, J.; Proctor, W. Collaborative approaches to water management and planning: An institutional perspective. Ecol. Econ. 2013, 86, 97-106. [CrossRef]

26. Holley, C.; Sinclair, D. Deliberative participation, environmental law and collaborative governance: Insights from surface and groundwater studies. Environ. Plan. Law J. 2013, 30, 32-55.

27. Chaffin, B.; Garmestani, A.; Gosnell, H.; Craig, R. Institutional networks and adaptive water governance in the Klamath River Basin, USA. Environ. Sci. Policy 2016, 57, 112-121. [CrossRef]

28. Fliervoet, J.M.; van den Born, R.J.; Meijerink, S.V. A stakeholder's evaluation of collaborative processes for maintaining multi-functional floodplains: A Dutch case study. Int. J. River Basin Manag. 2017, 15, 175-186. [CrossRef]

29. Stringer, L.C.; Reed, M.S.; Fleskens, L.; Thomas, R.J.; Le, Q.B.; Lala-Pritchard, T. A New Dryland Development Paradigm Grounded in Empirical Analysis of Dryland Systems Science. Land Degrad. Dev. 2017, $28,1952-1961$. [CrossRef]

30. Bodin, O.; Crona, B. The role of social networks in natural resource governance: What relational patterns make a difference? Glob. Environ. Chang. 2009, 19, 366-374. [CrossRef]

31. Prell, C.; Hubacek, K.; Reed, M. Stakeholder Analysis and Social Network Analysis in Natural Resource Management. Soc. Nat. Resour. 2009, 22, 501-518. [CrossRef]

32. Prell, C.; Reed, M.; Racin, L.; Hubacek, K. Competing structure, competing views: The role of formal and informal structures in shaping stakeholder perceptions. Ecol. Soc. 2010, 15, 34. [CrossRef]

33. Stein, C.; Ernstson, H.; Barron, J. A social network approach to analyzing water governance: The case of the Mkindo catchment, Tanzania. Phys. Chem. Earth Parts A/B/C 2011, 36, 1085-1092. [CrossRef] 
34. Larson, S.; Alexander, K.S.; Djalante, R.; Kirono, D.G.C. The Added Value of Understanding Informal Social Networks in an Adaptive Capacity Assessment: Explorations of an Urban Water Management System in Indonesia. Water Resour. Manag. 2013, 27, 4425-4441. [CrossRef]

35. Fliervoet, J.M.; Geerling, G.W.; Mostert, E.; Smits, A.J.M. Analyzing Collaborative Governance Through Social Network Analysis: A Case Study of River Management Along the Waal River in The Netherlands. Environ. Manag. 2016, 57, 355-367. [CrossRef]

36. Crona, B.; Bodin, O. What You Know is Who You Know? Communication Patterns Among Resource Users as a Prerequisite for Co-management. Ecol. Soc. 2006, 11, 7. [CrossRef]

37. Gálvez, V.; Rojas, R.; Bennison, G.; Prats, C.; Claro, E. Collaborate or perish: Water resources management under contentious water use in a semiarid basin. Int. J. River Basin Manag. 2019, doi:10.1080/15715124.2019.1634083. [CrossRef]

38. Cardwell, H.; Langsdale, S.; Stephenson, K. The Shared Vision Planning Primer: How to Incorporate Computer Aided Dispute Resolution in Water Resources Planning; Institute Water Resources, US Army Corps of Engineers: Washington, DC, USA, 2009.

39. Bourget, L. Converging Waters: Integrating Collaborative Modeling with Participatory Processes to Make Water Resources Decisions; IWR Press: Alexandria, VA, USA, 2011.

40. Reed, M.S.; Graves, A.; Dandy, N.; Posthumus, H.; Hubacek, K.; Morris, J.; Prell, C.; Quinn, C.H.; Stringer, L.C. Who's in and why? A typology of stakeholder analysis methods for natural resource management. J. Environ. Manag. 2009, 90, 1933-1949. [CrossRef] [PubMed]

41. Wasserman, S.; Faust, K. Social Network Analysis: Methods and Applications; Cambridge University Press: Cambridge, UK, 1994.

42. Dimadama, Z.; Zikos, D. Social Networks as Trojan Horses to Challenge the Dominance of Existing Hierarchies: Knowledge and Learning in the Water Governance of Volos, Greece. Water Resour. Manag. 2010, 24, 3853-3870. [CrossRef]

43. Lienert, J.; Schnetzer, F.; Ingold, K. Stakeholder analysis combined with social network analysis provides fine-grained insights into water infrastructure planning processes. J. Environ. Manag. 2013, 125, 134-148. [CrossRef] [PubMed]

44. Krupa, M.; Cenek, M.; Powell, J.; Trammell, E.J. Mapping the Stakeholders: Using Social Network Analysis to Increase the Legitimacy and Transparency of Participatory Scenario Planning. Soc. Nat. Resour. 2018, 31, 136-141. [CrossRef]

45. World Bank. Chile: Diagnóstico de la Gestión de los Recursos Hídricos; Technical Report; World Bank: Washington, DC, USA, 2011.

46. Retamal, M.R.; Andreoli, A.; Arumi, J.L.; Rojas, J.; Parra, O. Gobernanza del Agua y Cambio Climático: Fortalezas y Debilidades del Actual Sistema de Gestión del Agua en Chile. Análisis Interno. Interciencia 2013, 38, 8-16.

47. Hurlbert, M.A.; Diaz, H. Water Governance in Chile and Canada: A Comparison of Adaptive Characteristics. Ecol. Soc. 2013, 18. [CrossRef]

48. Hill, M. Climate Change and Water Governance; Springer: Cham, The Netherlands, 2013.

49. UN Environment. Progress on Integrated Water Resources Management. Global Baseline for SDG 6 Indicator 6.5.1: Degree of IWRM Implementation; UN Environment: Nairobi, Kenya, 2018.

50. Dourojeanni, A.; Chevaleraud, Y.; Acevedo Alvarez, P. Las Mesas del Agua y la Gestion de Cuencas en Chile. Estudio de Caso, Region de Atacama, Chile; Technical Report; Centro Atacama-Agua y Energía: Copiapó, Chile, 2010.

51. DGA. Atlas del Agua Chile 2016; Ministerio de Obras Públicas: Santiago, Chile, 2016; Chapter 4.

52. Fundación Chile. Reporte Huella hídrica en Chile. Sectores Prioritarios de la Cuenca del río Rapel; Technical Report; Fundación Chile: Santiago, Chile, 2015.

53. DGA. Información Pluviométrica, Fluviométrica, Estado de Embalses y Aguas Subterráneas; Technical Report 488; Dirección General de Aguas: Santiago, Chile, 2018.

54. Rojas, M.; Aldunce, P.; Farías, L.; González, H.; Marquet, P.; Muñoz, J.; Palma-Behnke, R.; Stehr, A.; Vicuña, S. Evidencia Científica y Cambio Climático en Chile: Resumen para Tomadores de Decisiones; Technical Report; Comité Científico COP25; Ministerio de Ciencia, Tecnología, Conocimiento e Innovación: Santiago, Chile, 2019. 
55. Davis, M.D. Integrated Water Resource Management in Chile: To Be or Not To Be. In Critical Transitions in Water and Environmental Resources Management; American Society of Civil Engineers: Reston, VA, USA, 2004.

56. Bitran, E.; Rivera, P.; Villena, M.J. Water management problems in the Copiapó Basin, Chile: Markets, severe scarcity and the regulator. Water Policy 2014, 16, 844-863. [CrossRef]

57. Prieto, M. Bringing water markets down to Chile's Atacama Desert. Water Int. 2016, 41, 191-212. [CrossRef]

58. Budds, J. Securing the market: Water security and the internal contradictions of Chile's Water Code. Geoforum 2018, doi:10.1016/j.geoforum.2018.09.027. [CrossRef]

59. Bauer, C.J. Against the Current: Privatization, Water Markets, and the State in Chile; Springer: New York, NY, USA, 1998.

60. Bauer, C.J. In the image of the market: The Chilean model of water resources management. Int. J. Water 2005, 3, 146-165. [CrossRef]

61. Bauer, C.J. Water conflicts and entrenched governance problems in Chile's market model. Water Altern. 2015, 8, 147-172.

62. Donoso, G. Overall Assessment of Chile's Water Policy and Its Challenges. In Water Policy in Chile; Springer International Publishing: Berlin/Heidelberg, Germany, 2018; pp. 209-219.

63. Basco-Carrera, L.; Warren, A.; van Beek, E.; Jonoski, A.; Giardino, A. Collaborative modelling or participatory modelling? A framework for water resources management. Environ. Model. Softw. 2017, 91, 95-110. [CrossRef]

64. Basco-Carrera, L.; Meijers, E.; Sarısoy, H.D.; Şanli, N.O.; Coşkun, S.; Oliemans, W.; van Beek, E.; Karaaslan, Y.; Jonoski, A. An adapted companion modelling approach for enhancing multi-stakeholder cooperation in complex river basins. Int. J. Sustain. Dev. World Ecol. 2018, 25, 747-764. [CrossRef]

65. Langsdale, S.; Beall, A.; Bourget, E.; Hagen, E.; Kudlas, S.; Palmer, R.; Tate, D.; Werick, W. Collaborative Modeling for Decision Support in Water Resources: Principles and Best Practices. J. Am. Water Resour. Assoc. 2013, 49, 629-638. [CrossRef]

66. Schneider, F.; Rist, S. Envisioning sustainable water futures in a transdisciplinary learning process: Combining normative, explorative, and participatory scenario approaches. Sustain. Sci. 2014, 9, 463-481. [CrossRef]

67. Tennekes, M. Treemap: Treemap Visualization. Technical Report. 2017. Available online: https://cran.r-project. org/web/packages/treemap/treemap.pdf (accessed on 24 November 2020).

68. Tabassum, S.; Pereira, F.S.F.; Fernandes, S.; Gama, J. Social network analysis: An overview. WIREs Data Min. Knowl. Discov. 2018, 8. [CrossRef]

69. Borgatti, S.; Everett, M.; Freeman, L. UCINET for Windows: Software for Social Network Analysis; Technical Report; Analytic Technologies: Harvard, MA, USA, 2002.

70. Borgatti, S.P.; Everett, M.G. Models of core/periphery structures. Soc. Netw. 2000, 21, 375-395. [CrossRef]

71. Borgatti, S.; Everett, M.; Johnson, J. Analysing Social Networks, 2nd ed.; SAGE: Los Angeles, CA, USA, 2018.

72. Mostert, E.; Craps, M.; Pahl-Wostl, C. Social learning: The key to integrated water resources management? Water Int. 2008, 33, 293-304. [CrossRef]

73. Reed, M.; Evely, A.; Cundill, G.; Fazey, I.; Glass, J.; Laing, A.; Newig, J.; Parrish, B.; Prell, C.; Raymond, C.; et al. What is social learning? Ecol. Soc. 2010, 15, 1-10. [CrossRef]

74. Sayles, J.S.; Baggio, J.A. Who collaborates and why: Assessment and diagnostic of governance network integration for salmon restoration in Puget Sound, USA. J. Environ. Manag. 2017, 186, 64-78. [CrossRef] [PubMed]

75. Megdal, S.; Eden, S.; Shamir, E. Water Governance, Stakeholder Engagement, and Sustainable Water Resources Management. Water 2017, 9, 190. [CrossRef]

76. Bodin, O.; Crona, B.; Ernstson, H. Social Networks in Natural Resource Management: What Is There to Learn from a Structural Perspective? Ecol. Soc. 2006, 11, 1-8. [CrossRef]

77. Vignola, R.; McDaniels, T.L.; Scholz, R.W. Governance structures for ecosystem-based adaptation: Using policy-network analysis to identify key organizations for bridging information across scales and policy areas. Environ. Sci. Policy 2013, 31, 71-84. [CrossRef]

78. Sandström, A.; Rova, C. Adaptive Co-management Networks: A Comparative Analysis of Two Fishery Conservation Areas in Sweden. Ecol. Soc. 2010, 15, 1-23. [CrossRef] 
79. Ruzol, C.; Banzon-Cabanilla, D.; Ancog, R.; Peralta, E. Understanding water pollution management: Evidence and insights from incorporating cultural theory in social network analysis. Glob. Environ. Chang. 2017, 45, $183-193$. [CrossRef]

80. dos Muchangos, L.S.; Tokai, A.; Hanashima, A. Stakeholder analysis and social network analysis to evaluate the stakeholders of a MSWM system-A pilot study of Maputo City. Environ. Dev. 2017, 24, 124-135. [CrossRef]

81. Blanc, S.; Lingua, F.; Bioglio, L.; Pensa, R.; Brun, F.; Mosso, A. Implementing Participatory Processes in Forestry Training Using Social Network Analysis Techniques. Forests 2018, 9, 463. [CrossRef]

Publisher's Note: MDPI stays neutral with regard to jurisdictional claims in published maps and institutional affiliations.

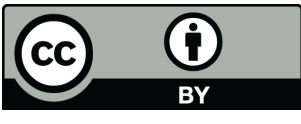

(c) 2020 by the authors. Licensee MDPI, Basel, Switzerland. This article is an open access article distributed under the terms and conditions of the Creative Commons Attribution (CC BY) license (http:/ / creativecommons.org/licenses/by/4.0/). 